UNIVERSIDADE DE SÃO PAULO

FACULDADE DE MEDICINA DE RIBEIRÃO PRETO

ALEXANDRE RODRIGUES GASPARI

Avaliação biológica de nanocarreadores de doxorrubicina em células de câncer de bexiga

Ribeirão Preto 
ALEXANDRE RODRIGUES GASPARI

\section{Avaliação biológica de nanocarreadores de doxorrubicina em células de câncer de bexiga}

Tese de Doutorado em Clínica Cirúrgica apresentada

à Faculdade de Medicina de Ribeirão Preto da Universidade de São Paulo para obtenção do título de doutor em Ciências.

Área de Concentração: Cirurgia e Anatomia

Orientador: Prof. Dr. Rodolfo Borges dos Reis

Ribeirão Preto 
Autorizo a reprodução e divulgação total ou parcial deste trabalho, por qualquer meio convencional ou eletrônico, para fins de estudo e pesquisa, desde que citada a fonte.

Gaspari, Alexandre Rodrigues

Avaliação biológica de nanocarreadores de doxorrubicina em células de câncer de bexiga. Ribeirão Preto, 2018. 58p.

Tese de Doutorado em Clínica Cirúrgica apresentada à Faculdade de Medicina de Ribeirão Preto da Universidade de São Paulo. Área de concentração: Cirurgia e Anatomia.

Orientador: Reis, Rodolfo Borges dos.

1.Câncer de bexiga. 2. Doxorrubicina. 3. Carreadores lipídicos nanoestruturados 


\section{FOLHA DE APROVAÇÃO}

Gaspari, Alexandre Rodrigues

Avaliação biológica de nanocarreadores de doxorrubicina em células de câncer de bexiga.

Tese de Doutorado em Clínica Cirúrgica apresentada à Faculdade de Medicina de Ribeirão Preto para obtenção do Título de Doutor em Ciências.

Área de Concentração: Cirurgia e Anatomia

Orientador: Prof. Dr. Rodolfo Borges dos Reis

Aprovado em:

Banca Examinadora

Prof. Dr.

Instituição:

Julgamento:

Prof. Dr.

Instituição:

Julgamento:

Prof. Dr.

Instituição:

Julgamento: 


\section{AGRADECIMENTOS}

Agradeço a Deus pela dádiva da vida, pela famíla linda que me deu e por mais essa oportunidade de crescimento profissional, pessoal e também espiritual.

Agradeço à minha família: minha esposa Priscyla e meus filhos Davi e Giovana. Com vocês ao meu lado, sinto-me completo. Obrigado por todo apoio. Principalmente seu apoio Pry. Sem ele, eu não conseguiria chegar até aqui. Esta vitória é nossa.

Ao meu orientador Rodolfo, por aceitar o desafio de juntos desbravar novas áreas em busca de novos conhecimentos.

A minha amiga Mariza, agradeço muito por toda a sua ajuda. Você sempre foi uma amiga muito generosa. Torço muito por você e pelo Michael. Que Deus te abençoe muito!

Aos amigos do laboratório Nanobiolab: Cenzi, Taís, Carol, Mariza, Letícia, Ivana, Ana Helena, Joice, Patrícia, Thaís. Obrigado pela amizade de vocês e por tantos momentos alegres.

As minhas amigas Margarete e Juliana. Muito obrigado pela amizade de vocês. Margarete, obrigado por sua ajuda. Sucesso sempre!

Aos amigos Claudinha e Renato, da FMRP, obrigado pela amizade e pela torcida.

As amigas Laucéa e Juliana da Pós-graduação da FMRP, obrigado por toda ajuda que vocês me deram. 
"A fé é a certeza de que vamos receber as coisas que esperamos e a prova de que existem coisas que não podemos ver."

Hebreus 11.1 


\section{RESUMO}

GASPARI, Alexandre Rodrigues Gaspari. Avaliação biológica de nanocarreadores de doxorrubicina em células de câncer de bexiga. 2018. 58p. Tese (Doutorado em Clínica Cirúrgica) - Faculdade de Medicina de Ribeirão Preto, Universidade de São Paulo, Ribeirão Preto, 2018.

O carcinoma da bexiga urinária $(\mathrm{CB})$ é a segunda doença maligna mais frequente do trato urinário. Devido a baixa eficácia dos tratamentos intravesicais atuais (imunoterapia com BCG e quimioterapia), seja pelo baixo tempo de residência do fármaco na bexiga ou pela baixa permeabilidade no urotélio, novas estratégias que aumentem esse tempo de residência do fármaco e sua penetração na bexiga têm sido investigadas. Dentre estas estratégias pode-se citar os sistemas de liberação sustentada nanoestruturados, que liberam o fármaco gradativamente, protegem o fármaco encapsulado, aumenta a biodisponibilidade, aumentando a eficácia da terapia e diminuindo os efeitos adversos. Nesta linha, o objetivo desse trabalho foi produzir e utilizar carreadores lipídicos nanoestruturados (CLN) como sistema de carreamento de doxorrubicina (DOXO) e a sua avaliação biológica em células de câncer de bexiga. Os CLN, compostos por manteiga de Illipê (lipídeo sólido), ácido oleico (óleo) e o estabilizante Pluronic F68, foram preparados pelo método de emulsão a quente e sonicação. A caracterização físico-química do CLN foi realizada determinando o diâmetro hidrodinâmico médio e potencial zeta (carga superficial) por espalhamento de luz dinâmico (DLS), cristalinidade por calorimetria exploratória diferencial (DSC), eficiência de encapsulamento por espectrofotometria UV-vis, ensaio de citotoxicidade em células RT4 e análise de permeação ex vivo e in vivo das formulações aplicadas em bexiga de porco por microscopia confocal. O diâmetro hidrodinâmico médio dos CLN sem o fármaco foi de $103 \mathrm{~nm}$ e seu PdI (índice de polidispersão) igual a 0,2. O encapsulamento da DOXO aumentou o diâmetro dos CLN para $112 \mathrm{~nm}$ e o valor de PdI foi de 0,2. O baixo valor de PdI indica formulações com baixa polidispersão. Os valores de potencial zeta dos CLN sem e com DOXO foram ambos negativos, variando de $-5 \mathrm{mV}$ a $-25 \mathrm{mV}$. Nos termogramas das amostras de CLN-DOXO não foi observado o pico referente a fusão da DOXO em $197,93^{\circ} \mathrm{C}$, indicando que o fármaco provavelmente está molecularmente disperso na matriz lipídica. Nos ensaios de citotoxicidade, a formulação CLN-DOXO mostrou-se mais citotóxica do que a DOXO livre em baixas concentrações $(31-250 \mathrm{ng} / \mathrm{mL})$. $\mathrm{O}$ valor de $\mathrm{IC}_{50}$ reduziu 2,1 vezes quando a DOXO foi encapsulada. Essa maior atividade antitumoral in vitro pode estar relacionada ao aumento do uptake celular como confirmado pelos ensaios de citometria de fluxo. No estudo de permeação ex vivo em bexiga de porco foram observadas permeações muito semelhantes das formulações de DOXO livre e encapsulada em CLN. Porém no ensaio in vivo a DOXO encapsulada permeou mais que a DOXO livre. Os resultados obtidos apontam para um promissor sistema de liberação de doxorrubicina para a terapia do câncer de bexiga.

Palavras-chave: Câncer de bexiga. Doxorrubicina. Carreadores lipídicos nanoestruturados. 


\section{ABSTRACT}

\section{GASPARI, Alexandre Rodrigues Gaspari. Biological evaluation of doxorubicin}

nanocarriers in bladder cancer cells. 2018. 58p. Tese (Doutorado em Clínica Cirúrgica) Faculdade de Medicina de Ribeirão Preto, Universidade de São Paulo, Ribeirão Preto, 2018. Urinary bladder carcinoma (BC) is the second most common malignant disease of the urinary tract. Due to the low efficacy of current intravesical treatments (BCG immunotherapy and chemotherapy), either because of the low residence time of the drug in the bladder or due to low permeability in the urothelium, new strategies that increase the residence time of the drug and its penetration into the bladder have been investigated. These strategies include nanostructured sustained release systems, which release the drug gradually, protect the encapsulated drug, increase the bioavailability; increasing the effectiveness of the therapy and reducing side effects. In this line, the aim of this work was to produce and apply nanostructured lipid carriers (NLC) as a doxorubicin delivery system (DOXO) and its biological evaluation in bladder cancer cells. The NLC, composed by Illipe butter (solid lipid), oleic acid (oil) and Pluronic F68 stabilizer, were prepared by the hot emulsion and sonication method. The physical-chemical characterization of these NLC was performed by measured the mean hydrodynamic diameter and zeta potential (surface charge) by dynamic light scattering (DLS), crystallinity by differential scanning calorimetry (DSC), encapsulation efficiency by UV-vis spectrophotometry, cytotoxicity assay in RT4 cells and ex vivo and in vivo permeation assay of formulations applied to pig bladder by confocal microscopy. The mean hydrodynamic diameter of NLC without the drug was $103 \mathrm{~nm}$ and its PdI (polydispersity index) was 0.2. The encapsulation of DOXO increased the NLC diameter to $112 \mathrm{~nm}$ and the PdI value was 0.2. The low value of PdI indicates formulations with low polydispersion. The zeta potential values of the NLC without and with DOXO were both negative $(-5 \mathrm{mV}$ to $-25 \mathrm{mV})$. In the thermograms of the NLC-DOXO sample the fusion peak of DOXO at 197.93 was not observed, indicating that the drug is molecularly dispersed in the lipid matrix. In the cytotoxicity assays, the NLC-DOXO formulation was more cytotoxic than free DOXO at low concentrations (31-250 ng/mL). The $\mathrm{IC}_{50}$ value was reduced 2.1 fold when DOXO was encapsulated. This increased in vitro antitumor activity may be related to increased cell uptake as confirmed by flow cytometry analysis. In the ex vivo permeation study in the pig bladder, a very similar permeation was observed between free and encapsulated DOXO. However, in the in vivo assay the encapsulated DOXO permeated more than free DOXO. The results indicates a promising release system of doxorubicin to bladder cancer therapy.

Keywords: Bladder cancer. Doxorubicin. Nanostructured lipid carriers. 


\section{LISTA DE FIGURAS}

Figura 1 Representação das taxas de incidência de neoplasia maligna da bexiga por 100 mil homens (à esquerda) e por 100 mil mulheres (à direita), estimadas para o ano de 2018. 13

Figura 2 Fórmula estrutural do cloridrato de doxorrubicina 15

Figura 3 Esquematização estrutural dos carreadores lipídicos nanoestruturados (CLN): A) CLN imperfeito, B) CLN amorfo, C) múltiplo CLN

Figura 4 Método de preparação de CLN (emulsão à quente e sonicação)

Figura 5 Célula de difusão do tipo Franz utilizada no experimento de permeação 30

Figura 6 Fragmento da bexiga congelada em tissue-tek 30

Figura 7 Diâmetro hidrodinâmico de uma nanopartícula 33

Figura 8 Medida do pontecial zeta de uma nanopartícula 34

Figura 9 Perfil de distribuição de diâmetro hidrodinâmico do CLN sem DOXO (curva em vermelho) e do CLN-DOXO (curva em verde). 35

Figura 10 Variação do diâmetro hidrodinâmico médio e PdI dos CLN sem DOXO (A) e CLN-DOXO (B) em função do tempo 36

Figura 11 Variação do potencial zeta dos CLN vazio (A) e CLN-DOXO (B) em função do tempo... 37

Figura 12 Curva analítica da Doxorrubicina.... 38

Figura 13 Termogramas dos componentes Manteiga de Illipê e Pluronic F68 39

Figura 14 Termogramas da Doxorrubicina, CLN vazio e CLN-DOXO.... 40

Figura 15 Perfil do diâmetro hidrodinâmico e potencial Zeta dos CLN-DOXO em função do pH..... 42

Figura 16 Variação do potencial zeta em função da concentração de mucina adicionada em CLN-

DOXO

Figura 17 Viabilidade de células RT4 em função das diferentes concentrações de CLN-DOXO e DOXO livre após o intervalo de 24 horas

Figura 18 Viabilidade de células RT4 em função das diferentes concentrações de CLN-DOXO e DOXO livre após o intervalo de 48 horas 45

Figura 19 Uptake celular da DOXO livre e do CLN-DOXO em células de câncer de bexiga RT4 .... 47

Figura 20 Imagens de um microscópio confocal de uma bexiga de porco após $1 \mathrm{~h}$ em contato com CLN sem DOXO (A, B e C), com DOXO livre (D, E e F) e DOXO encapsulada em CLN (CLNDOXO) $(\mathrm{G}, \mathrm{H}$ e I)

Figura 21 Imagens de um microscópio confocal de uma bexiga de porco após $1 \mathrm{~h}$ em contato com DOXO livre (A, B e C) e DOXO encapsulada em CLN (CLN-DOXO) (D, E e F). 


\section{LISTA DE TABELAS}

Tabela 1 Valores de diâmetro hidrodinâmico médio, índice de polidispersão (PdI) e potencial zeta (PZ), dos CLN com e sem doxorrubicina 35

Tabela 2 Resultados de precisão (DPR) e exatidão (E). 38

Tabela 3 Valores de entalpia de fusão, ponto de fusão e índice de recristalização (IR) dos componentes Pluronic F68, manteiga de Illipê e dos CLN sem e com Doxorrubicina.. 41 


\section{SUMÁRIO}

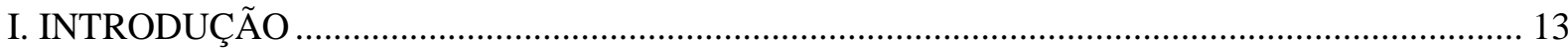

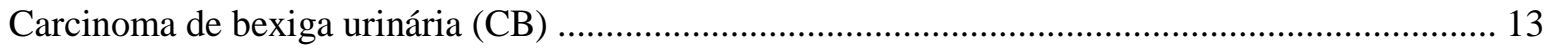

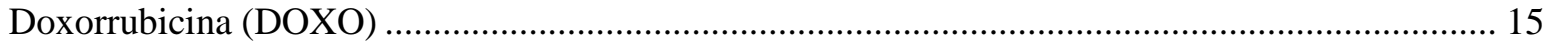

Nanopartículas Lipídicas Sólidas (NLS) e Carreadores Lipídicos Nanoestruturados (CLN) ........... 16

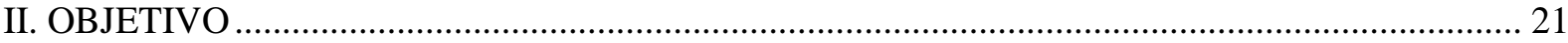

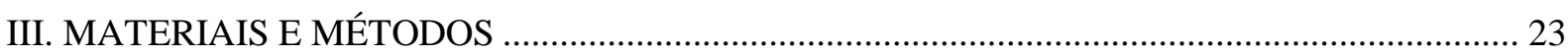

A. Preparo dos Carreadores Lipídicos Nanoestruturados (CLN) ..................................................... 23

B. Caracterização físico-química dos Carreadores Lipídicos Nanoestruturados (CLN) ................... 24

B.1. Determinação do diâmetro hidrodinâmico médio e do potencial zeta dos CLN .................... 24

B.2. Determinação da eficiência de encapsulamento (EE) da Doxorrubicina................................ 24

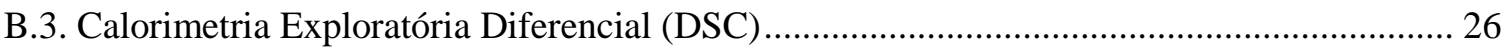

B.4. Efeito do pH no diâmetro hidrodinâmico médio e potencial zeta dos CLN-DOXO .............. 27

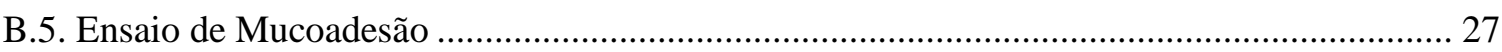

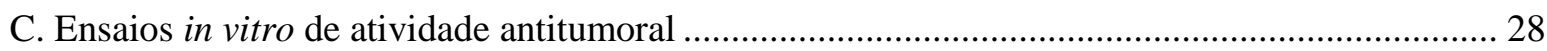

C.1. Ensaio de citotoxicidade utilizando o corante vermelho neutro ........................................... 28

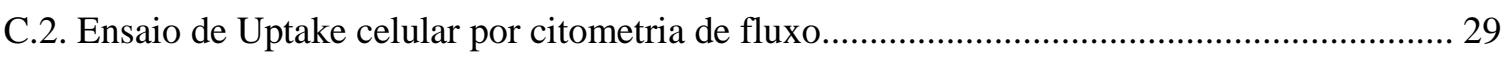

D. Ensaios ex vivo e in vivo de permeação em bexiga de porco ....................................................... 29

D.1. Ensaio ex vivo de permeação em bexiga de porco.................................................................. 29

D.2. Ensaio in vivo de permeação em bexiga de porco ................................................................ 31

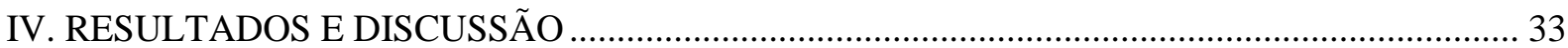

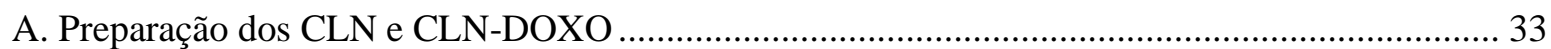

A.1. Determinação do diâmetro hidrodinâmico médio e do potencial zeta dos CLN .................... 33

A.2. Avaliação da eficiência de encapsulamento da doxorrubicina ............................................... 37

A.3. Cristalinidade dos Carreadores Lipídicos Nanoestruturados.................................................. 39

A.4. Avaliação da influência do pH nas propriedades físicas dos CLN........................................ 41

A.5. Avaliação da propriedade de mucoadesão dos CLNs através da sua interação com mucina 42

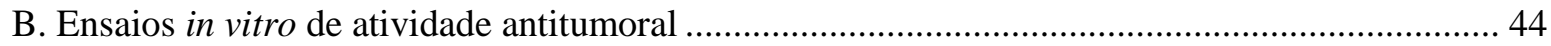

B.1. Ensaio de citotoxicidade utilizando o corante vermelho neutro ............................................ 44

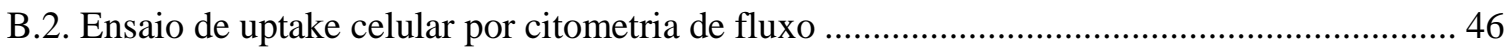

C. Ensaios ex vivo e in vivo de permeação em bexiga de porco.......................................................... 47

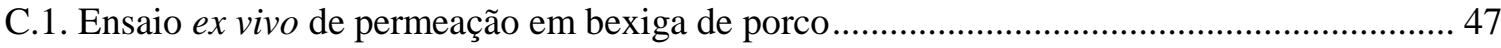

C.2. Ensaio in vivo de permeação em bexiga de porco ..................................................................... 49

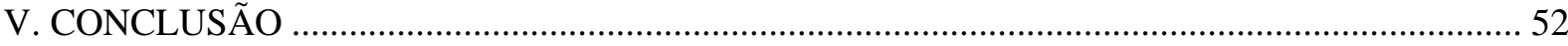

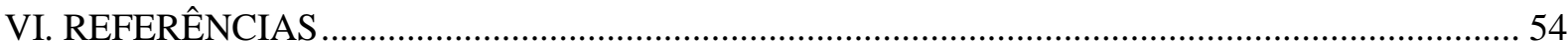


I. Introdução 


\section{INTRODUÇÃO}

\section{Carcinoma de bexiga urinária (CB)}

O carcinoma da bexiga urinária $(\mathrm{CB})$ é a segunda doença maligna mais frequente do trato urinário (REIS et al., 2012). No mundo é o nono tipo de neoplasia maligna mais incidente, com aproximadamente 430 mil novos casos em 2012. Quando comparado por sexo, nos homens, 330.380 casos novos, no mundo, em 2012, e nas mulheres 99.413 casos novos (FERLAY et al., 2013). Para o Brasil, estimam-se 9.480 novos casos de câncer de bexiga para cada ano do biênio 2018-2019, sendo 6.690 em homens e 2.790 em mulheres (INCA, 2018). Esses valores correspondem a um risco estimado de 6,43 casos novos a cada 100 mil homens e de 2,63 casos novos para cada 100 mil mulheres. A figura 1 mostra a incidência de câncer de bexiga em homens e mulheres em cada estado da federação.

Figura 1 Representação das taxas de incidência de neoplasia maligna da bexiga por 100 mil homens (à esquerda) e por 100 mil mulheres (à direita), estimadas para o ano de 2018.

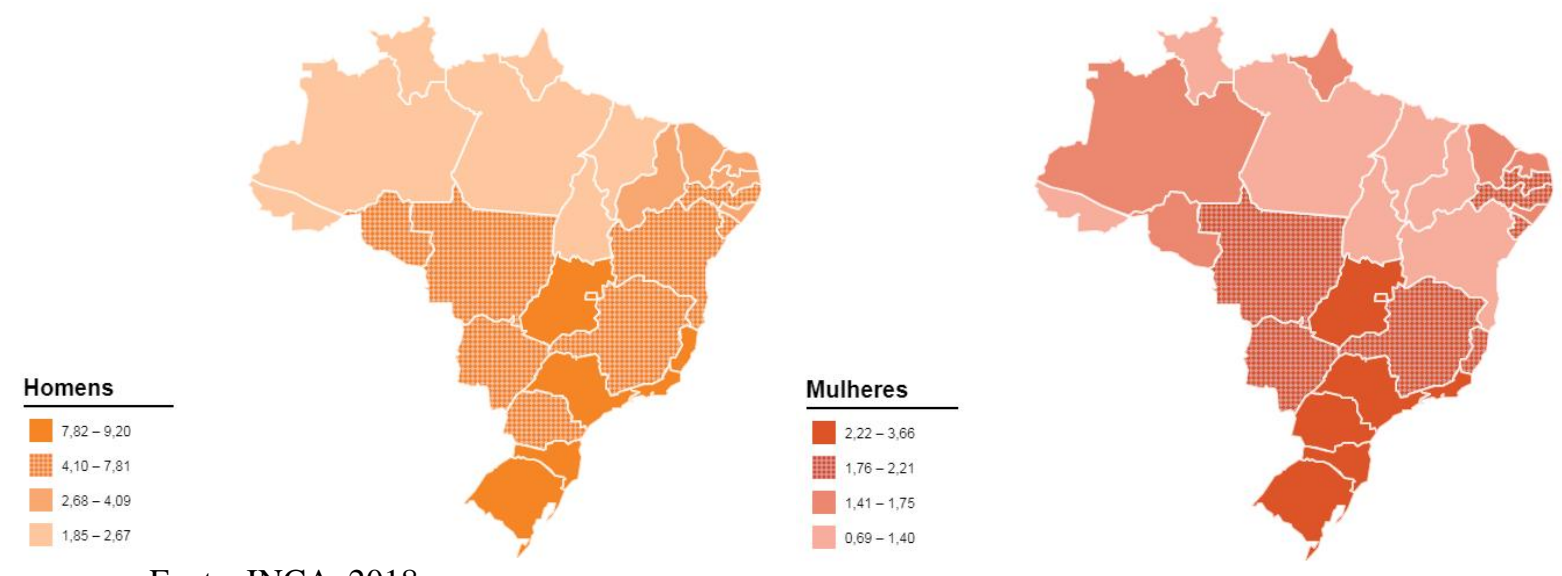

Fonte: INCA, 2018

Nas últimas décadas, tem sido observado um aumento significativo na incidência do câncer de bexiga no mundo, e isso pode ser uma consequência dos efeitos do tabagismo, que é reconhecido como importante fator de risco para o câncer (FREEDMAN et al., 2011). Segundo o World Cancer Report, estima-se que o risco de desenvolver câncer de bexiga entre os fumantes foi de duas a seis vezes maior em comparação aos não fumantes; sendo responsável por, aproximadamente, $66 \%$ dos casos novos em homens e 30\% dos casos novos em mulheres (STEWART; WILD, 2014). Também existe associação a fatores de risco relacionados à exposição ocupacional e ambiental, a exemplo do trabalho na produção de 
alumínio, exposição à emissão de gases de combustão de diesel, exposição a agrotóxicos, trabalho na indústria da borracha, do plástico, da indústria têxtil; assim como em atividades laborativas bem específicas: pintores, cabeleireiros e barbeiros que trabalham com tinturas (STEWART; WILD, 2014).

Quanto à mortalidade, para 2012, no mundo, foram estimados 165.084 óbitos com uma taxa de mortalidade de 2,3/100 mil, sendo que, para os homens, o óbito pela neoplasia maligna de bexiga representou 123.051 (3,5/100 mil) e, para as mulheres, 42.033 (1,2/100 mil) de todas as mortes por câncer (FERLAY et al., 2013). No Brasil, ocorreram, em 2015, 2.663 óbitos por câncer de bexiga em homens e 1.240 em mulheres (BRASIL, 2017).

O câncer de bexiga (CB) é classificado como não-invasivo quando se desenvolve e se mantém na parede do urotélio (GRASSO M., 2008) e invasivo quando se distribui na lâmina própria ou na camada muscular da bexiga (GLOBOCAN, 2008). Mais de $70 \%$ da incidência de CB é superficial, tumor não-invasivo, e a ocorrência de uma doença invasiva é ocasional (KROFT \& OYASU, 1994; REIS et al., 2009). Contudo, 50\% dos tumores não-invasivos recorrem em 4 anos após o tratamento e 11\% evoluem para o fenótipo invasivo (SHELLEY; MASON; KYNASTON, 2010; SHIMADA et al., 2011).

O tratamento do CB depende do grau de evolução da doença. Em casos mais avançados, pode-se optar pela cistectomia parcial ou total que compreendem a retirada parcial ou completa da bexiga, respectivamente. No $\mathrm{CB}$, caracterizado por lesões superficiais, a primeira escolha de tratamento é a instilação intravesical do bacilo Calmette-Guerin (BCG) (TRABOULSI \& KASSOUF, 2016). O tratamento com BCG foi inicialmente proposto por Morales et al. (1976) e desde então é utilizado após a ressecção transuretral do tumor para evitar a recidiva da doença (HERR; DALBAGNI; DONAT, 2011). No entanto, o uso desses organismos vivos ou atenuados causam efeitos colaterais, presentes em mais de $90 \%$ dos pacientes tratados com BCG. Os sintomas vão desde irritação leve do trato urinário até óbito, passando por complicações graves como instabilidade hemodinâmica, febre persistente ou reações alérgicas, comprometendo a utilização do BCG (SHELLEY; MASON; KYNASTON, 2010; TRABOULSI \& KASSOUF, 2016).

Alguns quimioterápicos como a doxorrubicina e a cisplatina são utilizados como alternativa à instilação intravesical de BCG, apesar das altas taxas de recorrência após o tratamento (cerca de 80\%). No caso de tumores superficiais, a administração sistêmica de quimioterápicos não é indicada, pois estes tumores estão localizados perto da superfície do urotélio que é pouco vascularizada (TSALLAS; JACKSON; BURT, 2011; TAN et al., 2016). Assim, a terapia intravesical com quimioterápicos é mais indicada, pois a administração do 
fármaco no local de ação pode aumentar a eficácia farmacológica e diminuir a dose necessária para a obtenção do efeito desejado, bem como diminuir os efeitos adversos (CAPAZ; SABAN; BONAMINI, 1988).

A bexiga é um órgão de fácil acesso e adequado para terapia local. Por esta via é possível expor a área lesionada diretamente ao fármaco e a quantidade de fármaco administrado pode ser facilmente controlada (ADIYAT; KATKOORI; SOLOWA, 2010). Entretanto, os fármacos possuem baixo tempo de residência na bexiga sendo constantemente removidos do urotélio devido ao esvaziamento e preenchimento periódico da urina na bexiga. Desta forma, várias administrações são necessárias podendo ocasionar dor local e infecções. Outro problema corresponde à baixa permeabilidade dos fármacos no urotélio, diminuindo a eficácia do tratamento. Em função destes obstáculos, algumas estratégias têm sido desenvolvidas, como por exemplo, a utilização de nanocarreadores de fármacos que podem aumentar sua penetração no urotélio, seu tempo de permanência na bexiga, além de apresentarem uma liberação sustentada, diminuindo assim o número de administrações (ALI et al., 2011).

\section{Doxorrubicina (DOXO)}

A doxorrubicina (DOXO) (figura 2) é um antibiótico de antraciclina com atividade antineoplásica. A DOXO é indicada no tratamento de vários tipos de câncer, tais como leucemia linfoblástica aguda, leucemia mieloblástica aguda, carcinoma de células transicionais de bexiga, carcinoma de mama, neuroblastoma, tumor de Wilms, carcinoma ovariano, carcinoma de tireoide, carcinoma prostático, linfomas de Hodgkin e não-Hodgkin, sarcoma de Ewing (SHEN, 2008). Ela é isolada da bactéria Streptomyces peucetius, e atua impedindo a replicação do DNA, inibindo assim a síntese de proteínas (BURGER et al, 2010).

Figura 2 Fórmula estrutural do cloridrato de doxorrubicina<smiles>COc1cccc2c1C(=O)c1c(O)c3c(c(O)c1C2=O)C[C@@](O)(C(=O)CO)C[C@H]3OC(C)C(N)O</smiles>

Fonte: https://www.sigmaaldrich.com/catalog/product/sigma/d1515?lang=pt\&region=BR 
A terapia do câncer de bexiga com a DOXO pode ser pela via intravenosa ou intravesical, sendo que esta última mostrou-se benéfica no tratamento do câncer superficial de bexiga, bem como na profilaxia de recidiva de tumor após ressecção transuretral (MANOHARAN, 2011).

A via de administração intravesical é utilizada no tratamento de carcinoma monocítico, tumores papilares da bexiga e carcinoma in situ para reduzir recidivas após ressecção transuretral (SUBEDI et al., 2009). Devido ao baixo pH do ambiente extracelular de tumores, fármacos fracamente básicos, como é o caso da doxorrubicina, são protonados diminuindo assim a sua absorção celular e, consequentemente, a eficácia da terapia (TRÉDAN et al., 2007). A administração pela via intravesical de DOXO foi estudada em pacientes imediatamente antes da cirurgia de cistectomia radical. Neste estudo foi observado que mais de $83 \%$ da DOXO administrada foi eliminada pela urina (após 2h) e uma baixa concentração de DOXO no urotélio, indicando que esse revestimento interno da bexiga é uma barreira eficaz para absorção de fármacos. Assim, novas estratégias têm sido buscadas para aumentar a eficácia da terapia com doxorrubicina. Uma das estratégias é o uso de nanopartículas como sistema de liberação sustentada de doxorrubicina, tais como nanopartículas lipídicas sólidas (NLS) e carreadores lipídicos nanoestruturados (CLN) (GLOBOCAN, 2008; WIENTJES et al., 1996).

\section{Nanopartículas Lipídicas Sólidas (NLS) e Carreadores Lipídicos Nanoestruturados (CLN)}

Nanopartículas lipídicas sólidas (NLS) têm sido intensamente estudadas como sistema de liberação de fármacos com intuito de manter o efeito do fármaco no tecido alvo, solubilizar fármacos lipofílicos, aumentar a penetração cutânea de moléculas, melhorar a estabilidade física e química de agentes terapêuticos, minimizar os efeitos colaterais e reduzir a toxicidade (SCHWARZ et al., 2012; JIANG et al., 2017). Além disso, estas partículas apresentam o potencial de aumentar a concentração de fármaco no tumor pelo efeito de aumento da permeabilidade e retenção (EPR) quando as partículas apresentam diâmetro entre 100-200 nm (ZWICKE et al., 2012; PIKTEL et al., 2016). Dentre as vantagens das NLS, pode-se citar a alta estabilidade temporal, alta capacidade de encapsulamento, baixo custo de produção e o fácil escalonamento. As NLS são biodegradáveis, biocompatíveis e têm alta capacidade de carrear fármacos com controle da sua liberação, sendo formadas por lipídios sólidos à temperatura ambiente e corporal, e estabilizadas por tensoativos (MARCATO, 2009; 
BAHARI; HAMISHEHKAR, 2016).

Carreadores lipídicos nanoestruturados (CLN) fazem parte da segunda geração de nanopartículas lipídicas, sucedendo as nanopartículas lipídicas sólidas (NLS). Estes carreadores (CLN) foram desenvolvidos com o intuito de melhorar a eficiência de encapsulamento e minimizar a expulsão do fármaco das nanopartículas durante o processo de estocagem, o que, em geral, ocorria com as NLS (LIU et al., 2010). Os CLN dividem-se em três diferentes estruturas:

- o primeiro modelo, conhecido como "CLN imperfeito" (Figura 3A) consiste em uma mistura de glicerídeos compostos por diferentes ácidos graxos. Essa mistura aumenta a distância entre as cadeias de ácidos graxos dos glicerídeos ocasionando imperfeições no cristal. Essas imperfeições geram mais espaço para acomodar o ativo, aumentando, assim, a eficiência de encapsulamento.

- O segundo modelo é chamado de "CLN amorfo" (Figura 3B), que corresponde a mistura de lipídios sólidos com lipídios líquidos (óleos). Essa estrutura evita a expulsão do ativo das nanopartículas durante a estocagem, já que a cristalização da matriz lipídica ocorre parcialmente.

- O terceiro modelo é chamado de "múltiplo CLN" (Figura 3C), formado por uma dispersão de óleo em lipídio sólido. Excede-se o valor de solubilidade do óleo no lipídio sólido, levando a uma separação de fase e formação de nanocompartimentos de óleo dentro da matriz lipídica sólida.

Figura 3 Esquematização estrutural dos carreadores lipídicos nanoestruturados (CLN): A) CLN imperfeito, B) CLN amorfo, C) múltiplo CLN
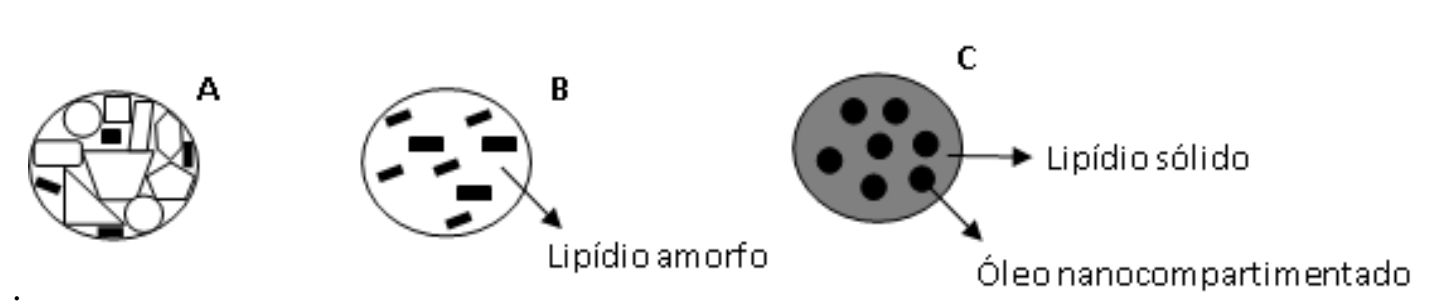

Fonte: MARCATO, 2009

Atualmente há uma busca por matérias-primas naturais que possam ser utilizadas na produção dos CLN como a manteiga de Illipê. Esta manteiga é produzida a partir das sementes das árvores do gênero Shorea, que podem ser encontradas na floresta de Bornéu. A manteiga de Illipê tem, em sua composição, ácidos graxos como o ácido esteárico (43,3\%), o 
ácido oleico (37,4\%) e o ácido palmítico (18\%) (GANI \& RAHMAN, 2010). Esta manteiga é sólida a temperatura ambiente, sua faixa de temperatura de fusão é de $34^{\circ}-38^{\circ} \mathrm{C}$, possui uma cor levemente amarelada e um aroma suave de noz. Sua escolha foi motivada pela presença de dois ácidos graxos: o ácido esteárico e o ácido oleico. Miryaghoubzadeh et al. (2013) avaliaram a composição de ácidos graxos em amostras de tecidos normais e malignos da bexiga de 31 pacientes. Nesse estudo, os autores observaram uma diferença na composição dos ácidos graxos existentes nestes dois tipos de tecidos, encontrando níveis mais altos de ácido esteárico e ácido oleico nos tecidos cancerígenos em comparação aos tecidos normais, confirmando assim a hipótese de que a atividade metabólica pode diferir nestes dois tipos de tecidos. Dessa forma, um carreador nanoestruturado contendo esses ácidos graxos pode ter maior afinidade com as células tumorais.

Os CLN vêm sendo investigados como sistema de encapsulamento de moléculas visando o tratamento do câncer. Quercetina (QT) foi encapsulada em carreador lipídico nanoestruturado (CLN) e sua atividade foi avaliada em células de câncer de mama (MCF-7 e MDA-MB-231). Os CLN foram preparados com os lipídios sólidos gliceril tridecanoato e gliceril tripalmitato e com o lipídio oleoso acetato de tocoferol (Vitamina E). Neste estudo foi verificado que CLN-QT aumentou significativamente a citotoxicidade sendo este efeito dose dependente (1-50 mM) e induziu apoptose (na concentração de $20 \mathrm{mM}$ de QT) nas células MCF-7 e MDA-MB-231. Os autores indicaram que o aumento da citotoxicidade e da apoptose pode estar relacionado com o aumento da absorção de QT pelas células cancerígenas quando esta está encapsulada nos CLN (VARSHOSAZ et al, 2012). Em outro estudo, carreadores lipídicos nanoestruturados com ácido ursólico encapsulado foram testados em células de melanoma humano B16 e células leucêmicas K562. Os resultados demonstraram que em $24 \mathrm{~h}$ o $\mathrm{IC}_{50}$ para o ácido ursólico livre foi de $7,7 \mu \mathrm{M}$, enquanto que, para o encapsulado foi de $0,041 \mu \mathrm{M}$ em células B16. Já nas células K562, os valores do $\mathrm{IC}_{50}$ para o ácido ursólico livre e encapsulado foram 224,38 $\mu \mathrm{M}$ e $0,14 \mu \mathrm{M}$, respectivamente. Esses valores de $\mathrm{IC}_{50}$ sugerem uma atividade superior para o ácido ursólico encapsulado em relação a sua forma livre (NAHAK et al, 2016).

Doxorrubicina juntamente com o análogo da vitamina E, o succinato de $\alpha$-tocoferol, foram encapsulados em NLS para avaliar o aumento do efeito antitumoral em células de câncer de mama MCF-7. As NLS com doxorrubicina e com succinato de $\alpha$-tocoferol demonstraram maior citotoxicidade frente as células de câncer de mama MCF-7 em relação à doxorrubicina livre, apresentando um $\mathrm{IC}_{50}$ 6,5 vezes menor (OLIVEIRA et al, 2016). Dessa forma, os CLN apresentam grande potencial como sistema de carreamente de fármacos para a 
terapia de diferentes tipos de câncer. Entretanto, para a aplicação dessas partículas com eficácia e segurança as mesmas precisam ser caracterizadas por diferentes técnicas físicoquímicas visto que essas propriedades influenciam nos efeitos biológicos das partículas (ARORA et al, 2012). 
II. Objetivo 


\section{OBJETIVO}

Avaliação biológica de um carreador lipídico nanoestruturado contendo doxorrubicina em células de câncer de bexiga, visando o aumento da eficácia desse tratamento. 
III. Materiais e Métodos 


\section{MATERIAIS E MÉTODOS}

\section{A. Preparo dos Carreadores Lipídicos Nanoestruturados (CLN)}

Esta etapa do projeto foi realizada em parceria com a Profa. Dra. Priscyla Daniely Marcato Gaspari da FCFRP-USP.

Os CLN sem e com o fármaco (doxorrubicina) foram preparados pelo método de emulsão a quente e sonicação. Inicialmente, foram preparados $25 \mathrm{~mL}$ de fase aquosa contendo o estabilizante Pluronic F68 $(1 \% \mathrm{~m} / \mathrm{v})$. Em outro béquer, foi preparada a fase lipídica que consistiu em $250 \mathrm{mg}$ de manteiga de Illipê (lipídeo sólido) e $50 \mathrm{mg}$ de ácido oléico (óleo). Ambas fases, aquosa e lipídica, foram aquecidas, em banho-maria, até atingirem a temperatura de $80^{\circ} \mathrm{C}$ e, em seguida, a fase aquosa foi vertida sobre a fase lipídica. Esse sistema foi levado para a sonicação por 10 minutos em um sonicador de ponta (Sonics VCX, ponta de $13 \mathrm{~mm}$ e amplitude de 40\%). Após a sonicação, a dispersão foi resfriada em banho de água até a temperatura ambiente $\left(25^{\circ} \mathrm{C}\right)$, obtendo dessa forma, os carreadores lipídicos nanoestruturados (CLN). Já para o preparo dos CLN com o fármaco, $5 \mathrm{mg}$ de doxorrubicina (DOXO) foram adicionados na fase lipídica. Também foram preparados carreadores lipídicos nanoestruturados utilizando-se tampão Tris $(\mathrm{pH} 7,4,0,1 \mathrm{M})$ no lugar da água. A Figura 4 ilustra todo o processo de preparação desses carreadores lipídicos nanoestruturados.

Figura 4 Método de preparação de CLN (emulsão à quente e sonicação)
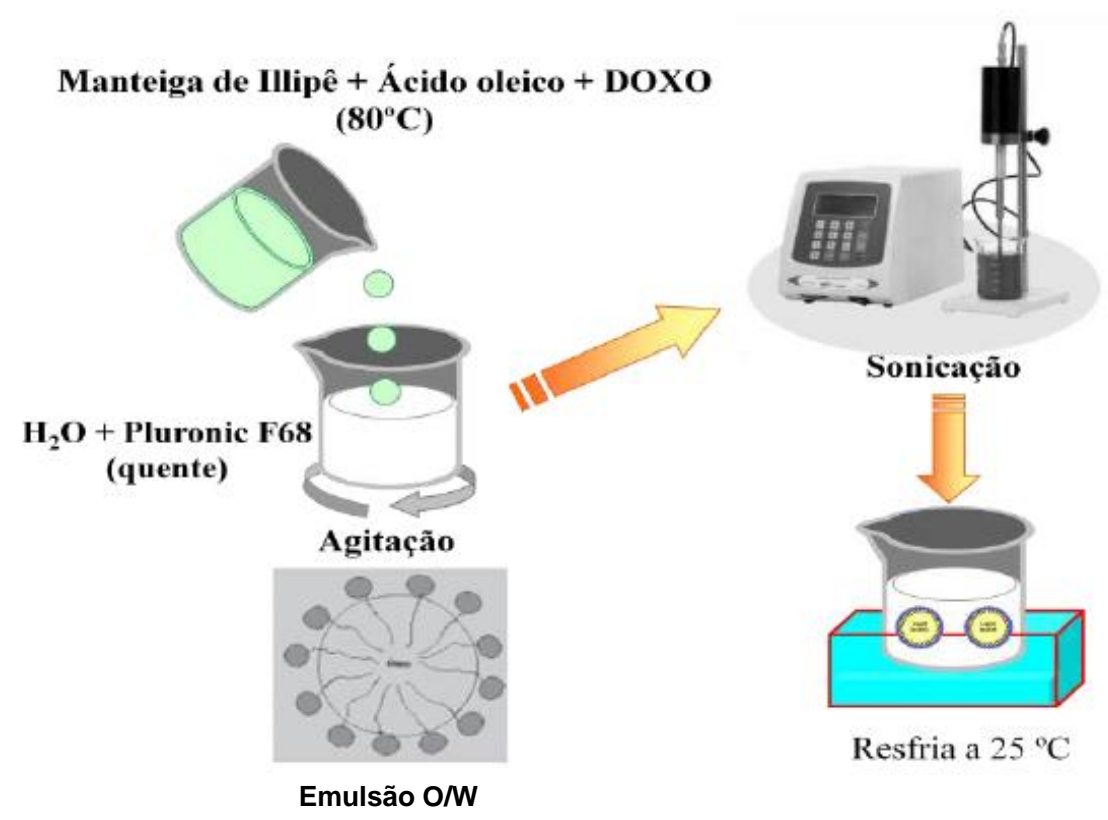

Fonte: Elaborada pelo autor 


\section{B. Caracterização físico-química dos Carreadores Lipídicos Nanoestruturados (CLN)}

\section{B.1. Determinacão do diâmetro hidrodinâmico médio e do potencial zeta dos CLN}

O diâmetro hidrodinâmico médio e o potencial zeta dos CLN produzidos foram determinados pela técnica de espalhamento de luz dinâmico (DLS), utilizando o aparelho NanoSize ZS (Malvern). Todas as medidas foram feitas em triplicata, após a diluição das amostras com solução de $\mathrm{KCl} 1 \mathrm{mM}$ na proporção de 1:100. A estabilidade das dispersões também foi avaliada, considerando o diâmetro hidrodinâmico médio (z-average), o valor de índice de polidispersão (PdI) e o potencial zeta em um intervalo de tempo de sessenta dias. Para isso, foram adicionadas às dispersões agentes antimicrobianos $(0,05 \% \mathrm{~m} / \mathrm{v}$ de metilparabeno e $0,15 \% \mathrm{~m} / \mathrm{v}$ de propilparabeno). As amostras foram mantidas sob refrigeração à temperatura de $4^{\circ} \mathrm{C}$.

\section{B.2. Determinação da eficiência de encapsulamento (EE) da Doxorrubicina}

\section{B.2.1. Validação do método analítico}

Para a realização da eficiência de encapsulamento foi, primeiramente, realizada a validação do método analítico por espectrofotometria no UV-vis conforme a Resolução RE 899 de 29 de maio de 2003. Os parâmetros de linearidade, precisão, exatidão e limite de quantificação e deteç̧ão foram avaliados.

Para a avaliação do parâmetro linearidade foi construída uma curva analítica com diferentes concentrações de doxorrubicina que foram avaliadas por espectrofotometria no ultravioleta-visível no comprimento de onda de máxima absorção da doxorrubicina (474 nm). Para isto, primeiramente foi preparada uma solução-mãe de doxorrubicina na concentração de $125 \mu \mathrm{g} / \mathrm{mL}$ em um balão de $25 \mathrm{~mL}$ usando água destilada como solvente. A partir desta solução foram preparadas soluções nas concentrações de $1,25 \mu \mathrm{g} / \mathrm{mL}, 2,5 \mu \mathrm{g} / \mathrm{mL}, 5 \mu \mathrm{g} / \mathrm{mL}$, $10 \mu \mathrm{g} / \mathrm{mL}, 20 \mu \mathrm{g} / \mathrm{mL}$ e $30 \mu \mathrm{g} / \mathrm{mL}$. Cada concentração foi avaliada no espectrofotômetro da PG Instruments (T70+SW). A curva foi validada pela repetição deste mesmo processo com leitura em triplicata para cada ponto. As curvas foram consideradas lineares quando apresentaram coeficiente de determinação $\left(\mathrm{R}^{2}\right)$ com valor superior a 0,99 .

A precisão de uma metodologia analítica expressa o quão próximo são os resultados obtidos entre uma série de medidas de uma amostragem múltipla de uma mesma amostra. $\mathrm{O}$ 
teste de precisão foi realizado para avaliar os critérios de repetitividade (precisão intraensaio). A determinação deste parâmetro foi realizada através da análise, em triplicata, de três soluções de doxorrubicina: $1,25 \mu \mathrm{g} / \mathrm{mL}, 5 \mu \mathrm{g} / \mathrm{mL}, 20 \mu \mathrm{g} / \mathrm{mL}$. Foram calculados o CV(\%) para três diferentes concentrações do analito em triplicata utilizando a equação $1 . \mathrm{Na}$ avaliação da precisão os valores máximos admitidos para $\mathrm{CV}(\%)$ foi de $5 \%$.

$$
\mathrm{CV}(\%)=(\mathrm{DP} / \mathrm{MD}) * 100
$$

em que,

$\mathrm{DP}=$ desvio padrão;

$\mathrm{MD}=$ média dos valores obtidos para concentração

A exatidão de uma metodologia analítica expressa a proximidade do resultado obtido com o valor real. A exatidão é expressa pela relação entre a concentração média determinada experimentalmente e a concentração teórica correspondente. Para a análise de exatidão, foram utilizadas as mesmas três concentrações determinadas para a análise da precisão, sendo analisadas em quintuplicata. A exatidão do método analítico foi determina pelos valores de recuperação médios obtidos nas três diferentes concentrações utilizando a equação 2 :

Exatidão $=(\mathrm{CMO}) /(\mathrm{CT}) \times 100$

(Equação 2)

em que,

$\mathrm{CMO}=$ concentração média obtida;

$\mathrm{CT}=$ concentração teórica.

O limite de quantificação e de detecção foram determinados. O limite de quantificação corresponde a menor quantidade de analito em uma amostra que pode ser determinada com precisão e exatidão aceitáveis sob as condições experimentais estabelecidas. O limite de quantificação foi calculado a partir da equação 3

$$
\mathrm{LQ}=\frac{\mathrm{DPa} \times 10}{\mathrm{IC}}
$$

em que, 
DPa é o desvio padrão do intercepto com o eixo Y

IC é a inclinação a partir das curvas construídas com as concentrações citadas.

O limite de detecção é a menor quantidade do analito presente em uma amostra que pode ser detectado, porém não necessariamente quantificado, sob as condições experimentais estabelecidas e foi calculado a partir da equação 4

$\mathrm{LD}=\frac{\mathrm{DPa} \times 3}{\mathrm{IC}}$

em que,

DPa é o desvio padrão do intercepto com o eixo $\mathrm{Y}$

IC é a inclinação a partir das curvas construídas com as concentrações citadas.

\section{B.2.2. Avaliação da eficiência de encapsulamento (EE\%)}

A eficiência de encapsulamento da doxorrubicina foi realizada por espectrofotometria UV-VIS no comprimento de onda de $474 \mathrm{~nm}$. Para isto, 0,5 $\mathrm{mL}$ da dispersão de nanopartículas contendo doxorrubicina foram adicionadas no sistema de filtração Microcon (MW $10 \mathrm{kDa}$, Millipore) e, em seguida, centrifugados por 10 minutos a $5000 \mathrm{x}$ g. A absorbância do filtrado foi medida em $474 \mathrm{~nm}$ no espectrofotômetro UV-VIS. A concentração foi calculada a partir da curva analítica previamente construída e validada. O valor obtido da concentração de doxorrubicina no filtrado $\left([\mathrm{DOXO}]_{\text {filtrado }}\right.$, que corresponde à concentração de doxorrubicina livre na formulação ([DOXO $]_{\text {livre }}$ ), foi subtraído da concentração total de doxorrubicina $\left([\mathrm{DOXO}]_{\text {total }}\right)$ na formulação de nanopartículas, obtendo-se assim a concentração de doxorrubicina encapsulada ([DOXO $\left.]_{\text {encap. }}\right)$. A EE\% foi calculada pela equação 5.

$\mathrm{EE}(\%)=\left([\mathrm{DOXO}]_{\text {encap }} /[\mathrm{DOXO}]_{\text {inicial }}\right) \times 100$

(Equação 5)

\section{B.3. Calorimetria Exploratória Diferencial (DSC)}

A cristalinidade das nanopartículas das amostras de CLN com e sem doxorrubicina assim como as matérias primas que as compõem (manteiga de Illipê, Pluronic F68 e 
doxorrubicina) foi determinada por Calorimetria Exploratória Diferencial (DSC). Para essa análise, as amostras de CLN com e sem DOXO foram previamente secas por liofilização.

Os termogramas de DSC foram obtidos em um Calorímetro Exploratório Diferencial DSC-Q10 (TA instruments) usando porta-amostra padrão de alumínio selado. As análises foram realizadas em atmosfera de nitrogênio (fluxo de $50 \mathrm{~mL} \cdot \mathrm{min}^{-1}$ ), na faixa de temperatura de 30 a $220^{\circ} \mathrm{C}$ (taxa de aquecimento de $10^{\circ} \mathrm{C} / \mathrm{min}$ ).

\section{B.4. Efeito do pH no diâmetro hidrodinâmico médio e potencial zeta dos CLN-DOXO}

A influência do pH no diâmetro hidrodinâmico médio e no potencial zeta dos CLNDOXO foi avaliada mediante o uso de um titulador (Malvern) acoplado ao NanoSize ZS (Malvern). Soluções aquosas de hidróxido de sódio e ácido clorídrico foram utilizadas como soluções titulantes nas concentrações $0,1 \mathrm{M} \mathrm{NaOH}, 0,25 \mathrm{M} \mathrm{NaOH}$ e $0,1 \mathrm{M} \mathrm{HCl}$. O diâmetro hidrodinâmico médio e o potencial Zeta foram medidos na faixa de $\mathrm{pH}$ de 6,0 - 8,0.

\section{B.5. Ensaio de Mucoadesão}

A mucoadesão refere-se à capacidade de uma estrutura ou molécula de aderir a mucosa dos tecidos por meio de interações iônicas com grupos funcionais negativos do muco ou por interações moleculares não covalentes, como ligação de hidrogênio e interações de Van der Waals com a superfície da mucosa (SMART, 2005; TRAPANI et al, 2014).

Para determinar a propriedade mucoadesiva das nanopartículas foi realizada uma titulação de mucina em uma dispersão de nanopartículas sem e com doxorrubicina e foi avaliado o potencial zeta das partículas em função da quantidade de mucina adicionada. Para isto, foi preparada uma solução de mucina de concentração de $2 \mathrm{mg} / \mathrm{mL}$ em tampão fosfato (100 mM, pH 6,2). A dispersão de nanopartículas foi diluída utilizando $20 \mu \mathrm{L}$ da mesma em $1980 \mu \mathrm{L}$ de uma solução de $\mathrm{KCl} 1 \mathrm{mM}$. A quantidade de mucina adicionada na dispersão de nanopartículas variou de $0-1,2 \mathrm{mg} / \mathrm{mL}$. Este estudo foi realizado utilizando um titulador MTP-2 Multi Purpose Titrator (Malvern) acoplado ao Zeta Sizer Malvern (NanoZS). Além disso, foi avaliado o diâmetro hidrodinâmico médio dos CLN antes e após a interação com a mucina. 


\section{Ensaios in vitro de atividade antitumoral}

\section{C.1. Ensaio de citotoxicidade utilizando o corante vermelho neutro}

Utilizou-se nos ensaios de citotoxicidade a linhagem de câncer de bexiga RT4 obtidas do Banco de Células do Rio de Janeiro (BCRJ). As células foram mantidas em cultura contínua, através de repiques periódicos até atingirem a confluência de $80 \%$. O cultivo foi realizado em meio McCoy5A contendo $1 \%$ de antibiótico (Penicilina-Streptomicina), suplementado com 10\% de soro bovino fetal (SBF). As células foram desprendidas usando solução de tripsina $1 \mathrm{X}$ e contadas para cultivo e plaqueamento em câmera de Neubauer usando uma alíquota homogeneizada da suspensão celular com quantidade equivalente de solução de Azul de Tripan $\left(0,4 \%\right.$ v/v). A incubação foi realizada em estufa a $37{ }^{\circ} \mathrm{C}$ sob atmosfera úmida e com $5 \%$ de $\mathrm{CO}_{2}$.

Para o ensaio de citotoxidade, foram utilizadas placas de 96 poços. O plaqueamento foi realizado inoculando $5 \times 10^{4}$ células/mL. As células foram incubadas à $37^{\circ} \mathrm{C}$ por $24 \mathrm{~h} \mathrm{e}$, posteriormente, tratadas com diferentes concentrações de DOXO livre, CLN-DOXO e CLN sem DOXO (CLN). As concentrações avaliadas foram: 2000; 1000; 500; 250; 125; 62,5 e $31,25 \mathrm{ng}$ de DOXO/mL para DOXO livre e CLN-DOXO.

Após $24 \mathrm{~h}$ ou $48 \mathrm{~h}$ o meio de cultura contendo DOXO livre ou nanopartículas foi removido e as placas foram lavadas com PBS 1X. Posteriormente, foi adicionado meio McCoy 5A completo acrescido de vermelho neutro na concentração de $50 \mu \mathrm{g} / \mathrm{mL}$. Em seguida, as células foram incubadas por 3h, tempo necessário para a incorporação do corante pelos lisossomos das células RT4 viáveis.

Após este período o meio foi cuidadosamente retirado e foram adicionados $200 \mu \mathrm{L}$ da solução de fixação (formaldeído 1\% / carbonato de cálcio 1\% / 49\% água deionizada). Posteriormente, a solução de fixação foi descartada e todos os poços lavados com $200 \mu \mathrm{L}$ de solução salina $(0,9 \% \mathrm{NaCl})$.

Em seguida, $200 \mu \mathrm{L}$ de solução reveladora (Etanol 50\%/ ácido acético glacial $1 \%$ / água deionizada) foram adicionados aos poços. As placas foram, por fim, agitadas em um agitador de placas por $10 \mathrm{~min}$ e as absorvâncias foram medidas em Microplate reader (Molecular Devices- SPECTRAmax/Plus384) a $540 \mathrm{~nm}$. Para a determinação dos valores de $\mathrm{IC}_{50}$ foi utilizado o software Graph Pad Prism versão 5.01. 


\section{C.2. Ensaio de Uptake celular por citometria de fluxo}

Células RT4 foram inoculadas em placas de 24 poços a uma densidade de $5 \times 10^{5}$ células/mL usando-se meio de cultura McCoy’s (1 mL de meio/poço).

Após $24 \mathrm{~h}$ do plaqueamento, o meio de cultura foi removido e os poços lavados com 0,5 mL de PBS. Após remover o PBS, as células foram tratadas com DOXO livre ou CLNDOXO no dobro da concentração referente ao valor do $\mathrm{IC}_{50}$ de cada amostra. Para a formulação de CLN-DOXO utilizou-se $0,3836 \mu \mathrm{g} / \mathrm{mL}$ de DOXO e para a DOXO livre 0,803 $\mu \mathrm{g} / \mathrm{mL}$.

As células tratadas e controle foram re-incubadas por $6 \mathrm{~h}$. Decorrido tal período, as células foram tripsinizadas e a captação celular avaliada por citometria de fluxo utilizando um Citômetro Facscanto BD FACSCalibur ${ }^{\mathrm{TM}}$ equipado com 3 lasers (488, 633 e 405 nm). Foram coletados 10.000 eventos por amostra analisada. O ensaio foi realizado em triplicata para cada amostra.

\section{Ensaios ex vivo e in vivo de permeação em bexiga de porco}

\section{D.1. Ensaio ex vivo de permeação em bexiga de porco}

A bexiga de porco foi doada pela Faculdade de Medicina de Ribeirão Preto, oriunda de porcos utilizados em cirurgias experimentais realizadas na própria faculdade pelos alunos do departamento de urologia. Após a coleta da bexiga, essa foi lavada 3 vezes com solução fisiológica comercial, transferida para um béquer contendo essa mesma solução e transportada em uma caixa de isopor com gelo.

Para a realização do ensaio de permeação ex vivo, foi utilizada uma célula de difusão do tipo Franz, composta por uma célula de vidro doadora e uma receptora separada por uma membrana, que no caso deste estudo foi a bexiga de porco (Figura 5). 
Figura 5 Célula de difusão do tipo Franz utilizada no experimento de permeação

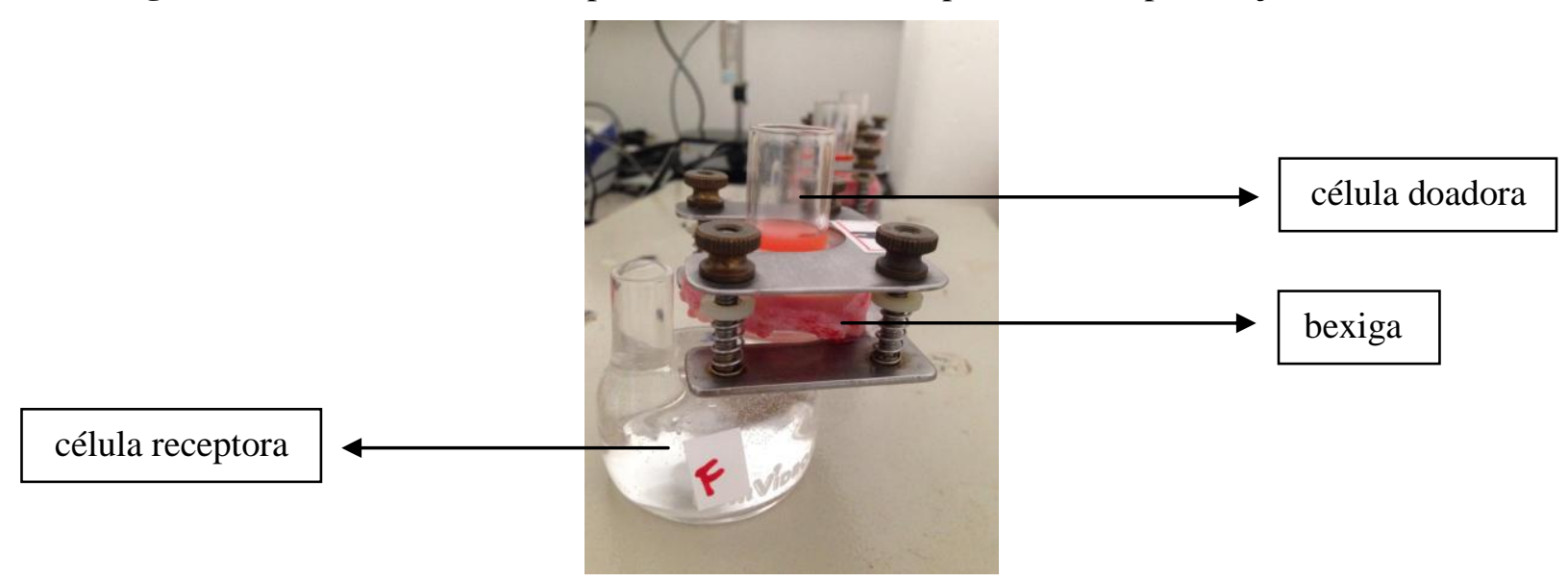

Fonte: Foto produzida pelo autor

A célula receptora foi preenchida com $34 \mathrm{~mL}$ de uma solução aquosa de tampão fosfato $(50 \mathrm{mM}, \mathrm{pH} 7,4)$. A bexiga foi cortada de acordo com o tamanho da célula de difusão $\left(8 \mathrm{~cm}^{2}\right)$ e colocada entre a célula receptora e a célula doadora, de tal forma que o urotélio ficasse voltado para a célula doadora. Foi adicionado na célula doadora $1 \mathrm{~mL}$ da formulação de CLN-DOXO, de DOXO livre na mesma concentração da formulação $(217 \mu \mathrm{g} / \mathrm{mL})$, da formulação de CLN sem o fármaco ou apenas do tampão. O sistema foi mantido por 1 hora após a adição da dispersão.

Após o tempo decorrido, retirou-se a bexiga e foram cortados fragmentos da parte central que ficou em contato com a dispersão para serem congelados em Tissue-tek, utilizando-se acetona e gelo seco. A figura 6 mostra um fragmento da bexiga congelada em Tissue-tek.

Figura 6 Fragmento da bexiga congelada em tissue-tek

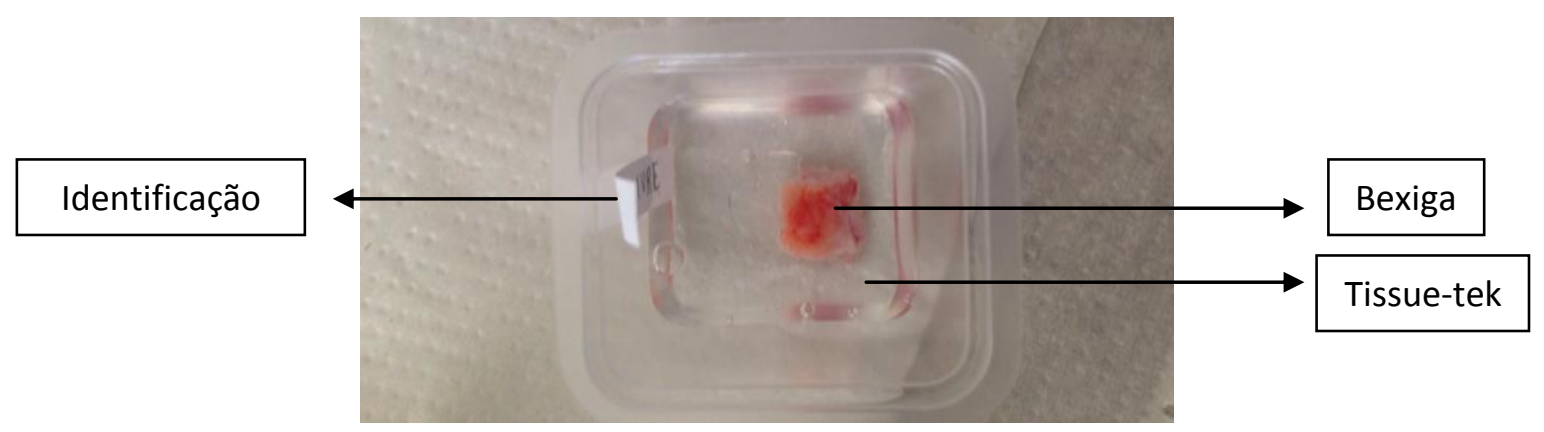

Fonte: Foto produzida pelo autor

O fragmento da bexiga congelado em tissue-tek foi submetido a cortes histológicos de $20 \mu \mathrm{m}$ de espessura com um criostato (Microm HM560). Esses cortes foram dispostos em 
lâminas e corados com DAPI (que marca o núcleo da célula). As lâminas foram observadas no microscópio confocal de varredura a laser (Zeiss LSM 510) usando filtros de comprimentos de onda de excitação de $405 \mathrm{~nm}$ para a DOXO e $358 \mathrm{~nm}$ para o DAPI.

\section{D.2. Ensaio in vivo de permeacão em bexiga de porco}

Os protocolos para realização dos estudos de permeação foram realizados de acordo com os princípios éticos de experimentação animal recomendados pelo Colégio Brasileiro de Experimentação animal (COBEA).

Com o animal anestesiado, uma fissura foi realizada na bexiga e essa foi lavada uma vez com solução fisiológica, com auxílio de uma sonda antes da adição da formulação.

Após ser lavada e esvaziada, cerca de $23 \mathrm{~mL}$ da formulação de CLN-DOXO ou DOXO livre foi adicionada na bexiga e mantida por 1h. Decorrido tal período, a bexiga foi removida, aberta e lavada com solução fisiológica. Em seguida, fragmentos de diferentes partes da bexiga foram retirados, congelados em tissue-tek para posterior corte e análise por microscópio confocal de varredura a laser. Os mesmos procedimentos descritos no tópico anterior para congelamento, corte e fixação dos tecidos foram seguidos para o processamento das amostras neste estudo in vivo. 
IV. Resultados e Discussão 


\section{RESULTADOS E DISCUSSÃO}

\section{A. Preparação dos CLN e CLN-DOXO}

\section{$\underline{\text { A.1. Determinação do diâmetro hidrodinâmico médio e do potencial zeta dos CLN }}$}

A avaliação do perfil de distribuição de diâmetro das partículas e do índice de polidispersão é fundamental no desenvolvimento de uma formulação nanoestruturada visto que esses parâmetros influenciam nos efeitos biológicos dessas nanoestruturas bem como na sua internalização celular e biodistribuição (LIN et al., 2013). Essa avaliação pode ser realizada pela técnica de espalhamento de luz hidrodinâmico. O diâmetro hidrodinâmico médio é calculado a partir das flutuações da intensidade de luz espalhada pelas nanopartículas em suspensão quando um laser incide sobre a amostra, utilizando a equação de StokesEinstein. Essas flutuações são resultado do movimento browniano das nanopartículas dispersas (SVILENOV e TZACHEV, 2014). A figura 7 mostra o diâmetro hidrodinâmico de um carreador lipídico nanoestruturado. Além da avaliação do diâmetro hidrodinâmico é possível, através dessa técnica obter o índice de polidispersão que está relacionado com a homogeneidade em relação ao diâmetro das partículas, sendo que valores abaixo de 0,25 indicam formulações com baixa polidispersão.

Figura 7 Diâmetro hidrodinâmico de uma nanopartícula

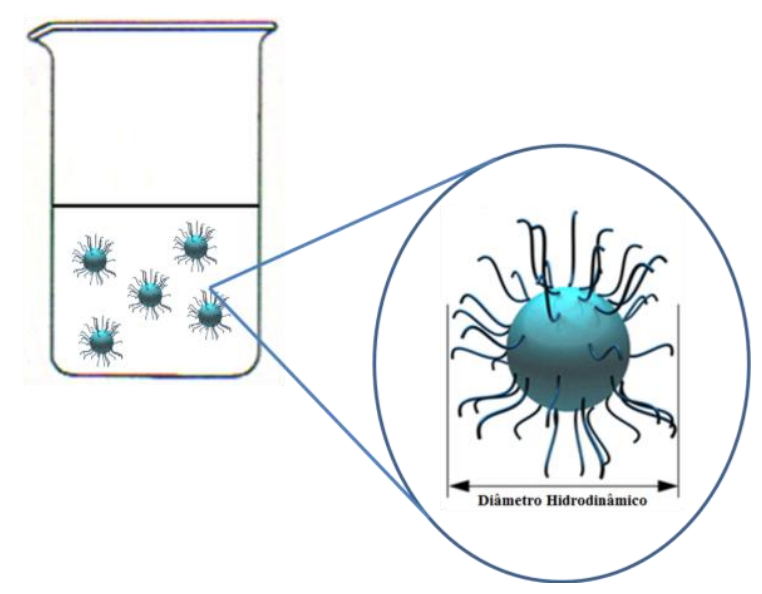

Fonte: Elaborada pelo autor

Outro parâmetro relevante na caracterização físico-química de nanopartículas é o potencial zeta. O potencial zeta é uma medida da carga superficial das partículas que pode ser utilizado para predizer o período de estabilidade das formulações, quando as partículas são 
estabilizadas apenas por carga (estabilidade elétrica). O potencial zeta é determinado no plano de cisalhamento como mostra a figura 8 (SVILENOV e TZACHEV, 2014).

Figura 8 Medida do potencial zeta de uma nanopartícula

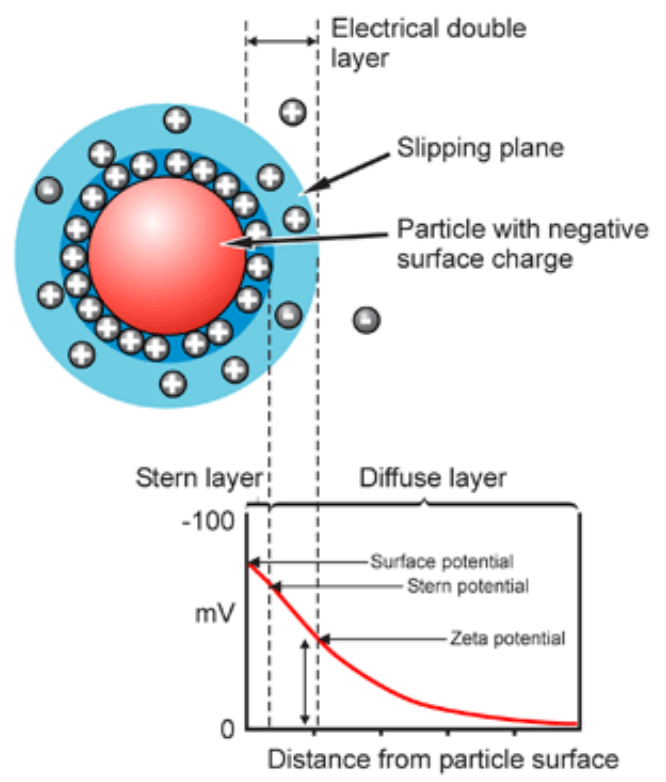

Fonte: https://nanocomposix.com/pages/characterization-techniques\#zeta-potential

Na Tabela 1, observa-se que o CLN sem doxorrubicina (vazio) apresentou um diâmetro hidrodinâmico médio de 103 nm. A adição de doxorrubicina (DOXO) à nanopartícula resultou em um aumento do seu diâmetro $(112 \mathrm{~nm})$, sendo um indicativo que o fármaco foi incorporado ao CLN. Quanto menor o diâmetro, maior a área superficial da nanopartícula e, consequentemente, maior serão as interações biológicas e absorção do fármaco encapsulado nessas partículas (MADANE e MAHAJAN, 2014). Dessa forma, esse reduzido diâmetro das partículas é interessante para a via intravesical. Senyigit et al. (2015) desenvolveram nanopartículas de quitosana com diâmetro médio de 175-190 nm e perfil monomodal de distribuição de tamanho para via intravesical na terapia do câncer superficial de bexiga. De acordo com os autores, os valores de diâmetro médio obtidos mostraram-se vantajosos, uma vez que nanopartículas $<400 \mathrm{~nm}$ são consideradas promissoras para aumentar a permeação nesses tecidos. Apesar de não ter na literatura estudos com nanopartículas lipídicas para a terapia do câncer superficial de bexiga, sabe-se que dentre as vantagens dos CLN destacam-se sua capacidade de originar formulações estáveis e formar filmes lipídicos capazes de proteger a superfície urotelial (GUHASARKAR e BANERJEE, 2010).

CLN e CLN-DOXO também foram preparados em tampão Tris com o objetivo de aumentar a eficiência de encapsulamento da DOXO que estava baixo. Em relação as 
propriedade físico-químicas, não foi observado alteração significativa $(\mathrm{p}<0,05)$ entre esses CLN e os CLN preparados com água (Tabela 1). O índice de polidispersão (PdI) para todas as formulações foi entre 0,195 e 0,198. O PdI é um indicativo da homogeneidade ou não das nanopartículas em relação ao seu tamanho, sendo que valores de PdI inferiores a 0,25 indicam baixa polidispersão com faixa estreita de distribuição de tamanho de partícula, sendo, portanto considerada ideal (TOMASINA et al., 2013). Desta forma, observando-se os resultados da Tabela 1, verifica-se que todas as formulações apresentaram baixa polidispersão. Além disso, foram obtidos CLN com distribuição de diâmetro monomodal como mostra a Figura 9.

Tabela 1 Valores de diâmetro hidrodinâmico médio, índice de polidispersão (PdI) e potencial zeta (PZ), dos CLN com e sem doxorrubicina.

\begin{tabular}{cccc}
\hline Partícula & Diâmetro $(\mathbf{n m})$ & PdI & PZ $(\mathbf{m V})$ \\
\hline \multicolumn{2}{c}{ Preparada com $\mathrm{H}_{2} \mathrm{O}$} & \\
\hline CLN & 103 & 0,196 & $-5,5$ \\
CLN-DOXO & 112 & 0,198 & $-19,0$ \\
\hline CLN & Preparada com Tampão Tris (pH 7,4) \\
\hline CLN-DOXO & 102 & 0,195 & $-8,0$ \\
\hline
\end{tabular}

Fonte: Elaborada pelo autor

Figura 9 Perfil de distribuição de diâmetro hidrodinâmico do CLN sem DOXO (curva em vermelho) e do CLN-DOXO (curva em verde).

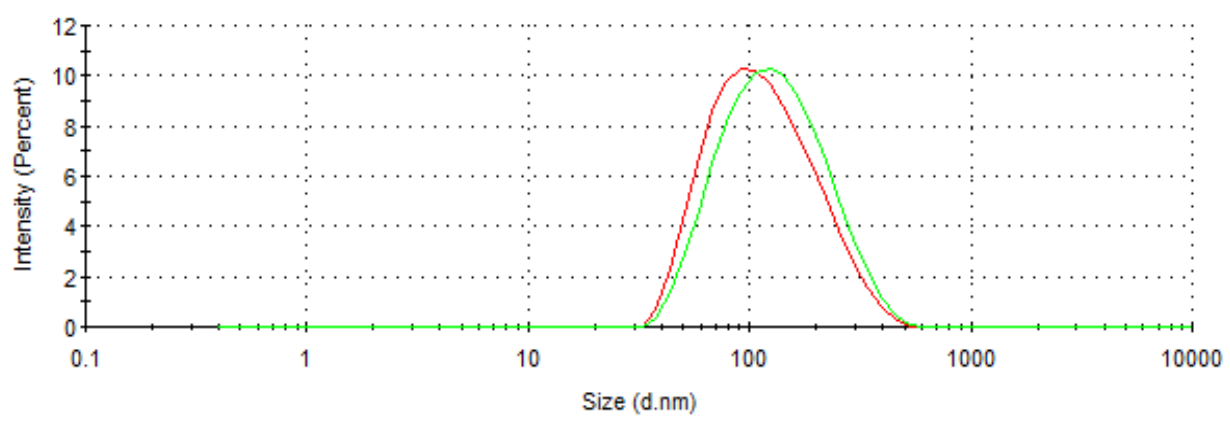

Fonte: Elaborado pelo autor

Todos os CLN apresentaram carga superficial negativa. Além disso, o valor de potencial zeta aumentou em módulo quando a DOXO foi encapsulada, indicando a sua interação com a superfície dos CLN. Entretanto, os valores de potencial zeta ficaram abaixo de $-30 \mathrm{mV}$. Nanopartículas, quando estabilizadas apenas por carga, são consideradas estáveis 
se apresentarem carga superficial maior que $30 \mathrm{mV}$ em módulo. Entretanto, quando estabilizadas por carga e impedimento estérico o valor de potencial zeta não pode ser utilizado como um parâmetro que define a estabilidade da formulação (PALLA \& SHAH, 2002). Como os CLN do presente trabalho foram preparados com o estabilizante Pluronic F68, que confere as partículas estabilidade eletroestérica, a estabilidade das partículas deve ser também avaliada em função do tempo e não apenas em função do valor do potencial zeta.

A literatura tem mostrado que NLS e CLN podem não ser estáveis em tempo prolongado quando em suspensão devido a processos como de gelificação e cristalização do sistema (MARCATO, 2009; GESZKE-MORITZ, 2016). Dessa forma, como foi utilizado estabilizante eletroestérico na preparação do CLN, foi realizada a avaliação da estabilidade dos CLN e CLN-DOXO em função do tempo. A Figura 10 apresenta os valores de diâmetro hidrodinâmico médio e índice de polidispersão (PdI) dos CLN e CLN-DOXO em função do tempo. Nesta figura, pode-se observar que os CLN mantiveram-se estáveis por 60 dias, não sendo observadas alterações no diâmetro e no PdI das partículas neste período. Já os CLNDOXO mantiveram-se estáveis por 30 dias, uma vez que em 60 dias houve um aumento do diâmetro das partículas, de $110 \mathrm{~nm}$ para $160 \mathrm{~nm}$, e do PdI, de 0,2 para 0,4, indicando o início da desestabilização do sistema.

Figura 10 Variação do diâmetro hidrodinâmico médio e PdI dos CLN sem DOXO (A) e CLN-DOXO (B) em função do tempo

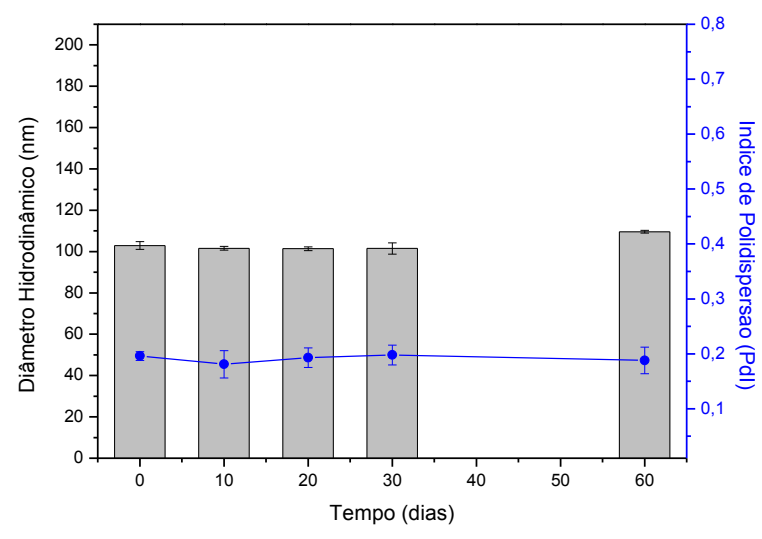

A

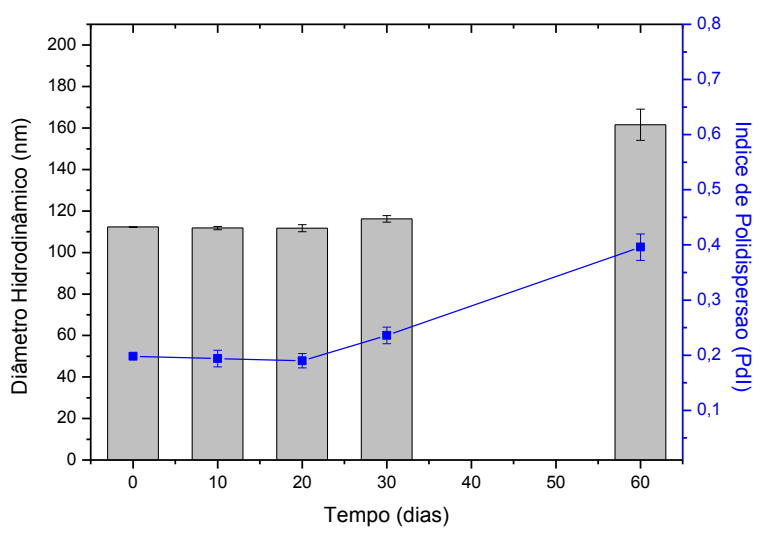

B

Fonte: Elaborados pelo autor

O potencial zeta dos CLN vazio e CLN-DOXO manteve-se negativo durante 60 dias como mostra a Figura 11. O valor do potencial zeta do CLN vazio aumentou em módulo com 
o tempo, enquanto que para os CLN-DOXO a variação do potencial zeta não foi significativa $(\mathrm{p}<0,05)$. Porém como discutido anteriormente, a estabilidade dos CLN não depende apenas de carga, mas também da estabilização por impedimento estérico e, portanto, as formulações podem ser consideradas estáveis no período avaliado.

Figura 11 Variação do potencial zeta dos CLN vazio (A) e CLN-DOXO (B) em função do tempo

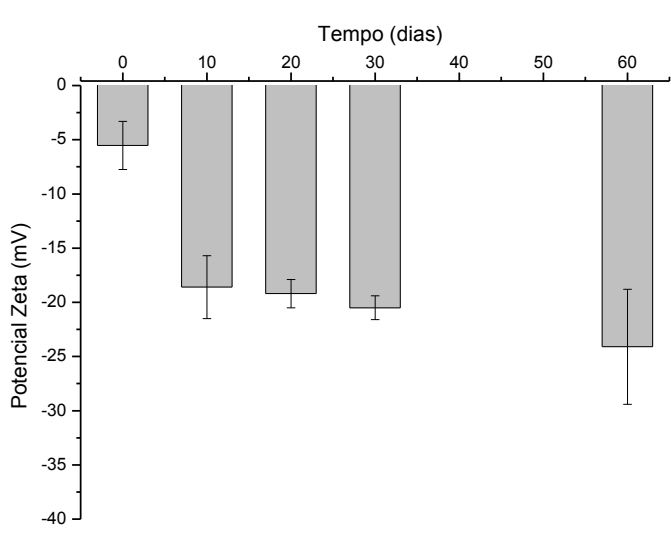

A

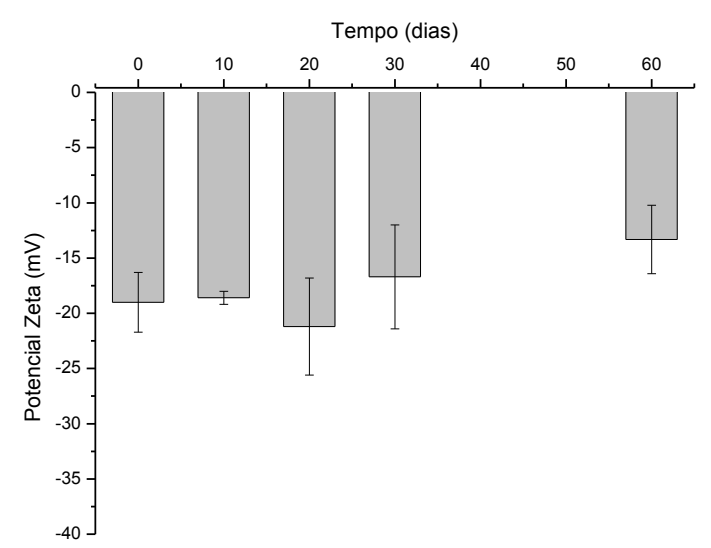

B

Fonte: Elaborados pelo autor

\section{$\underline{\text { A.2. Avaliacão da eficiência de encapsulamento da doxorrubicina }}$}

A eficiência de encapsulamento foi quantificada por espectrofotometria no UV-visível pois esta é uma técnica de execução simples e que apresenta resultados eficientes para análise de substâncias que apresentam absorção significativa nesta região do espectro. Os parâmetros avaliados para a validação do método analítico seguiram a determinação da ANVISA (RE 899, 2003). A Figura 12 mostra a curva analítica da doxorrubicina, no intervalo linear de concentração, para o comprimento de onda de $474 \mathrm{~nm}$. A equação de reta obtida foi y = $0,0063+0,02089 \mathrm{x}$ e o $R^{2}$ foi de 0,99966 indicando linearidade entre os pontos visto que o $R^{2}$ está dentro do valor preconizado pela RE 899 da ANVISA. 
Figura 12 Curva analítica da Doxorrubicina

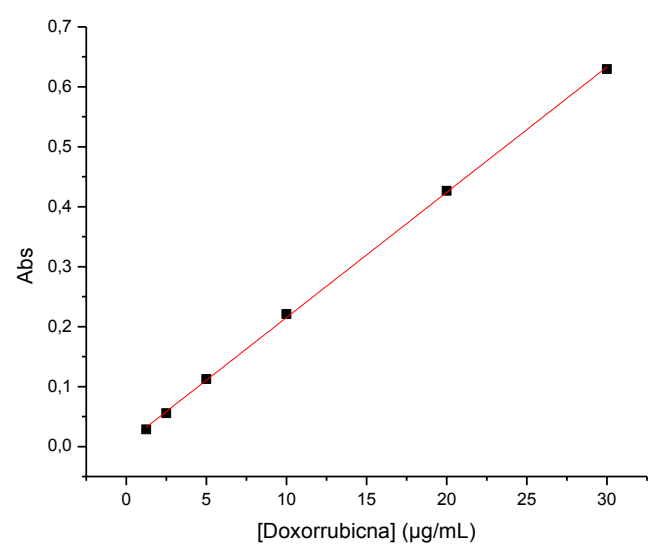

Fonte: Elaborado pelo autor

A Tabela 2 apresenta os valores de precisão (CV\%) e exatidão (E) para a metodologia utilizada, de forma que os valores de CV\% devem manter-se inferiores a $5 \%$ e a exatidão superior a 98\% de acordo com a RE 899 da ANVISA. A observação dos resultados expressos na Tabela 2 indica que o método atendeu às especificações, sendo, portanto, considerado preciso e exato. O limite de detecção e de quantificação foram, respectivamente, $0,38 \mu \mathrm{g} / \mathrm{mL}$ e $1,28 \mu \mathrm{g} / \mathrm{mL}$.

Tabela 2 Resultados de precisão (DPR) e exatidão (E)

\begin{tabular}{ccccc}
\hline $\begin{array}{c}\text { Concentração } \\
\text { teórica }(\mu \mathrm{g} / \mathrm{mL})\end{array}$ & $\begin{array}{c}\text { Concentração } \\
\text { média }(\mu \mathrm{g} / \mathrm{mL})\end{array}$ & $\begin{array}{c}\text { Desvio } \\
\text { Padrão }(\mathrm{DP})\end{array}$ & $\begin{array}{c}\text { Precisão } \\
(\mathrm{CV} \%)\end{array}$ & Exatidão (E) \\
\hline $\mathbf{1 , 2 5}$ & 1,149 & 0,0485 & $4,22 \%$ & $91,9 \%$ \\
$\mathbf{5}$ & 5,151 & 0,1167 & $2,27 \%$ & $103 \%$ \\
$\mathbf{2 0}$ & 20,128 & 0,1709 & $0,85 \%$ & $100,6 \%$ \\
\hline
\end{tabular}

Fonte: Elaborada pelo autor

A eficiência de encapsulamento (EE) da doxorrubicina foi calculada pelo método indireto, que consiste em determinar a quantidade de doxorrubicina que não foi encapsulada, e por diferença da quantidade total, determinar a quantidade do fármaco encapsulado. A EE obtida para os CLN produzidos com água foi de 55\%. Fármacos hidrofílicos quando encapsulados em matrizes lipofílicas tendem a apresentar baixa eficiência de encapsulamento (CRUZ et AL, 2009; BILENSOY et al, 2009). No entanto, quando os CLN foram preparados com tampão Tris, foi obtido um valor de EE de 94\%. Este aumento da EE pode estar 
relacionado com o pH do meio. O pKa da doxorrubicina é aproximadamente 7,4, desta forma, acima deste $\mathrm{pH}$ ocorre a desprotonação da amina presente na $\mathrm{DOXO}$, tornando-a menos hidrofílica e, portanto, com maior afinidade pela matriz lipídica. (DALMARK, 1981).

\section{A.3. Cristalinidade dos Carreadores Lipídicos Nanoestruturados}

O comportamento térmico dos CLN com e sem doxorrubicina e de seus componentes isolados foram avaliados por DSC. A Figura 13 mostra que a manteiga de Illipê apresenta um único pico endotérmico referente ao seu ponto de fusão em $36,35^{\circ} \mathrm{C}$ e o Pluronic $\mathrm{F} 68$ apresenta um único pico endotérmico referente ao seu ponto de fusão em $52,81^{\circ} \mathrm{C}$.

Figura 13 Termogramas dos componentes Manteiga de Illipê e Pluronic F68

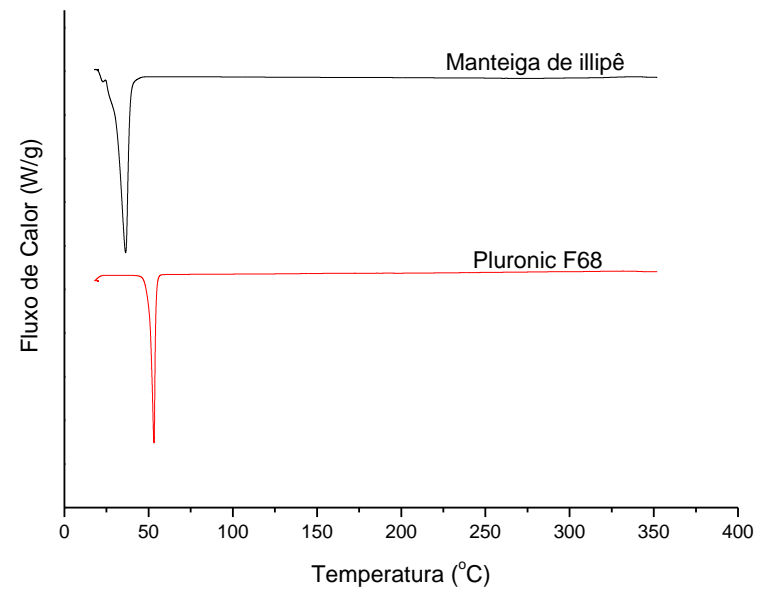

Fonte: Elaborado pelo autor

Na Figura 14 observa-se os termogramas da doxorrubicina, dos CLN vazio e dos CLN com doxorrubicina (CLN-DOXO). Na curva do CLN e CLN-DOXO, observa-se um pico referente a fusão da manteiga de Ilipê em uma temperatura um pouco abaixo da temperatura de fusão do lipídeo puro $\left(\sim 33^{\circ} \mathrm{C}\right)$. Esta redução pode ser explicada pelo reduzido diâmetro das partículas na faixa nanométrica, pela alta área superficial e pela presença de estabilizantes na superfície das partículas. Kelvin verificou que pequenas partículas isoladas apresentam uma redução da temperatura de fusão em relação ao material puro. Este evento é conhecido como pré-fusão ou efeito Kelvin (SURESH et al, 2007). Além disso, nos termogramas dos CLN vazios e dos CLN-DOXO, observa-se um pico referente ao estabilizante Pluronic F68 ao redor de $49^{\circ} \mathrm{C}$. A presença do pico de fusão do estabilizante nos termogramas de ambos CLN se deve à alta porcentagem do estabilizante utilizada para preparação das partículas $(1 \% \mathrm{~m} / \mathrm{v})$. 
A DOXO livre apresenta um pico endotérmico em $197,93^{\circ} \mathrm{C}$ (Figura 14). Entretanto, no termograma do CLN com DOXO não foi observado o pico endotérmico da DOXO indicando que a mesma, provavelmente, se encontra dissolvido na matriz lipídica e molecularmente dispersa na mesma (Figura 14) (SUN et al., 2014; ZIMMERMANN et al., 2005).

Figura 14 Termogramas da Doxorrubicina, CLN vazio e CLN-DOXO

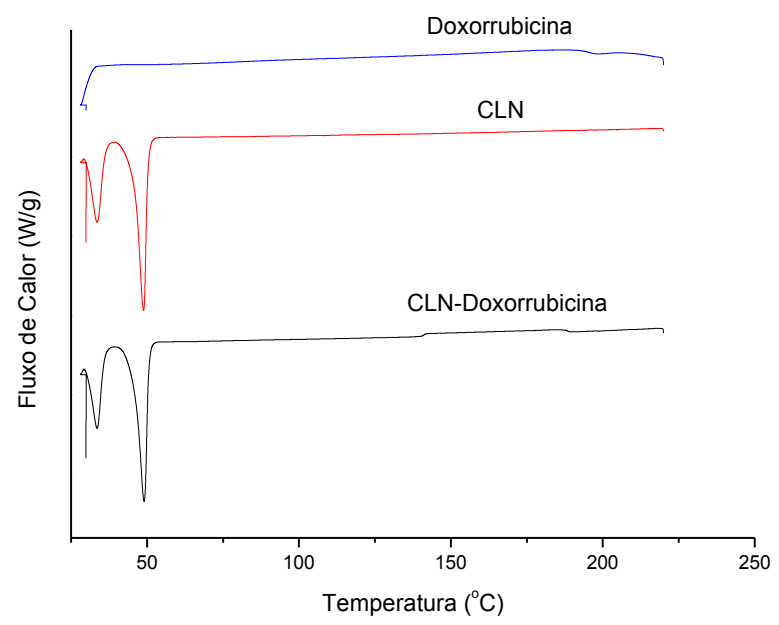

Fonte: Elaborado pelo autor

Na Tabela 3 estão apresentados todos os dados obtidos a partir dos termogramas das amostras. A entalpia de fusão é um parâmetro associado à organização cristalina do material sendo que quanto maior a organização do retículo cristalino, maior será a energia necessária para superar as forças de coesão da estrutura e, portanto, maior será a entalpia de fusão (MARCATO, 2009). Além disso, o grau de cristalinidade das partículas pode ser determinante na expulsão ou não do ativo durante o tempo de estocagem. No período de estocagem, o lipídeo que compõe as nanopartículas pode sofrer uma transformação em sua estrutura cristalina, caracterizada pela transição da forma cristalina polimórfica $\alpha$ (menos organizada) para a forma cristalina $\beta$ (mais organizada). Com o tempo, este aumento da transição para a forma $\beta$, resulta na formação de uma estrutura mais cristalina e, consequentemente, ocorre a expulsão do ativo (ATTAMA e MÜLLER-GOYMANN, 2008). Os CLN preparados apresentaram baixo valor de entalpia de fusão $(\Delta \mathrm{H})$ e de índice de recristalização (IR) como mostra a Tabela 3. Estes resultados demonstraram o caráter pouco cristalino das partículas preparadas com manteiga de Illipê e ácido oleico. Em geral, dispersões com alto IR mostraram acelerado crescimento do diâmetro das partículas com o tempo (baixa estabilidade) (FREITAS e MÜLLER, 1999). Portanto a redução da 
cristalinidade dos CLN em relação ao lipídio puro foi importante para obter-se uma alta eficiência de encapsulamento e uma alta estabilidade. Além disso, pode-se observar que quando a DOXO foi encapsulada no CLN, o IR aumentou indicando uma maior cristalinidade destas partículas em relação ao CLN sem DOXO. Esta diferença provavelmente ocorreu uma vez que o ativo ocupa os defeitos da estrutura cristalina das partículas ou regiões amorfas, aumentando, assim, a cristalinidade das mesmas.

Tabela 3 Valores de entalpia de fusão, ponto de fusão e índice de recristalização (IR) dos componentes Pluronic F68, manteiga de Illipê e dos CLN sem e com Doxorrubicina.

Material Entalpia de fusão $(\mathrm{J} / \mathrm{g}) \quad$ Ponto de Fusão $\left({ }^{\circ} \mathrm{C}\right) \quad$ Índice de

Recristalização

\begin{tabular}{cccc}
\hline Manteiga de Illipê & 135,7406 & 36,35 & $100 \%$ \\
Pluronic F68 & 124,5062 & 52,81 & - \\
DOXO & 1,9806 & 197,93 & - \\
CLN & 20,5686 & 33,64 & $33,34 \%$ \\
CLN-DOXO & 20,5094 & 33,60 & $33,54 \%$ \\
\hline
\end{tabular}

Fonte: Elaborada pelo autor

\section{A.4. Avaliação da influência do pH nas propriedades físicas dos CLN}

Nanopartículas possuem carga elétrica superficial devido à presença de grupamentos químicos do polímero ou do lipídio situados na superfície ou à adsorção preferencial de íons ou outras moléculas ionizáveis presentes no meio de dispersão aquoso (HATLEY e FRANKS, 1991). O valor do potencial zeta é influenciado por mudanças na interface das partículas com o meio externo, como a concentração de íons ou a dissociação/ionização de grupos funcionais presentes na superfície das partículas (FLORENCE e ATTWOOD, 2003). Desta forma, alterações no meio podem influenciar nos valores de potencial zeta das partículas. Essas alterações podem favorecer a aglomeração e coalescência das partículas desestabilizando a formulação. Dessa forma, a avaliação dessas alterações deve ser avaliada.

A Figura 15 apresenta os resultados de diâmetro hidrodinâmico e carga superficial dos CLN-DOXO em função do pH. Nesta figura, observa-se que com o aumento do pH do meio o valor do potencial zeta aumentou, em módulo, porém seu valor continuou negativo independente do $\mathrm{pH}$ do meio. $\mathrm{O}$ diâmetro das nanopartículas se manteve estável diante da variação de pH avaliada. Dessa forma, pode-se concluir que o CLN-DOXO apresentou alta estabilidade na faixa de $\mathrm{pH}$ de 6,0 a 8,0. 
Figura 15 Perfil do diâmetro hidrodinâmico e potencial Zeta dos CLN-DOXO em função do pH.

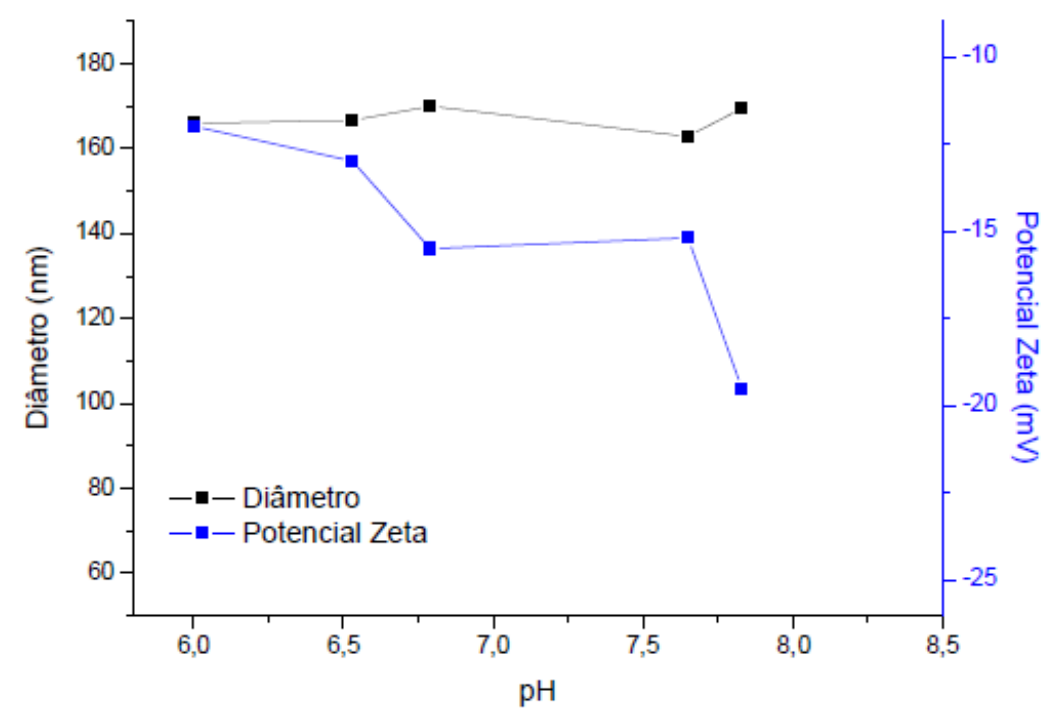

Fonte: Elaborado pelo autor

\section{A.5. Avaliação da propriedade de mucoadesão dos CLNs através da sua interacão com mucina}

Sistemas mucoadesivos apresentam um grande potencial para melhorar a eficácia de fármacos que irão agir ou serem absorvidos através das mucosas. Nanopartículas mucoadesivas podem prolongar o tempo de residência do fármaco no local de ação mediante contato com a mucosa. Os desafios envolvidos no desenvolvimento de sistemas mucoadesivos são grandes, mas podem levar a avanços importantes no desenvolvimento de formulações mais eficientes. Neste contexto, a mucoadesão torna-se uma estratégia interessante para promover a retenção do sistema e a liberação do fármaco, melhorando assim a sua ação (JASTI et al., 2003).

Existem diferentes teorias relacionadas ao processo de mucoadesão que envolvem a teoria da molhabilidade, onde componentes com baixa viscosidade ligam-se à superfície devido à mudança na energia superficial e interfacial; teoria da adsorção, no qual o sistema permanece conectado a mucosa por ligações de hidrogênio e interações Van der Waals; teoria eletrostática em que a interação ocorre quando a mucosa e o sistema apresentam diferentes cargas superficiais, entre outros. No entanto, o mecanismo básico envolvido na mucoadesão baseia-se no contato direto do sistema mucoadesivo e a membrana promovendo a molhabilidade e o intumescimento do sistema, e também na penetração do sistema no tecido ou na mucosa (MANSURI et al., 2016). 
Atualmente têm sido propostas várias metodologias para se estudar os mecanismos envolvidos na mucoadesão. Uma técnica qualitativa utilizada na verificação da propriedade mucoadesiva de nanopartículas é a interação de partículas com mucina. Esta pode ser realizada por meio de medidas de potencial zeta após o contato das partículas com a mucina (CARVALHO et al, 2010).

Para o estudo de mucoadesão dos carreadores lipídicos nanoestruturados, mucina foi adicionada à dispersão de nanopartículas. A Figura 16 mostra que ao adicionar quantidades crescentes de mucina, a carga residual negativa da dispersão de nanopartículas começa a reduzir, indicando a interação entre as nanopartículas e a mucina. Esta mucoadesão se deve às interações hidrofóbicas entre os domínios ricos em cisteína da mucina e os CLN (ZHANG et al., 2015).

Figura 16 Variação do potencial zeta em função da concentração de mucina adicionada em CLNDOXO

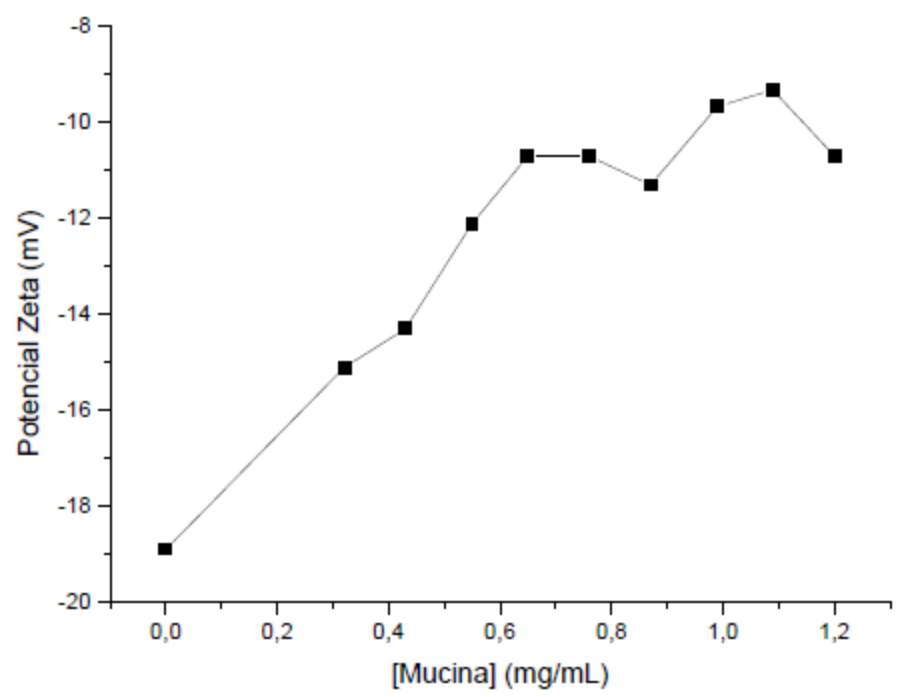

Fonte: Elaborado pelo autor

Além disso, foi avaliado o aumento do diâmetro das partículas quando a mesma interagia com mucina. Para isso, foi analisado uma solução de mucina, CLN-DOXO e CLNDOXO após a adição de $1,1 \mathrm{mg} / \mathrm{mL}$ de mucina pela técnica de DLS. Nesse estudo foi observado para a mucina um um perfil de distribuição de diâmetro bimodal com população com diâmetro médio de 1753 nm (90\%). O perfil de distribuição de diâmetro de CLN-mucina foi bimodal com $84,6 \%$ das partículas com diâmetro médio de 120,6 nm que corresponde ao CLN-DOXO e 15,4\% com diâmetro médio de 298,4 nm correspondente à interação CLNmucina. Desta forma, pode-se inferir que a CLN apresentou propriedade mucoadesiva devido 
aumento do diâmetro e alteração no potencial zeta das partículas quando em contato com a mucina.

\section{B. Ensaios in vitro de atividade antitumoral}

\section{B.1. Ensaio de citotoxicidade utilizando o corante vermelho neutro}

A avaliação de citotoxidade in vitro da doxorrubicina livre e encapsulada em CLN foi realizada em células de câncer de bexiga RT4 por ensaio de captura de vermelho neutro por se tratar de um teste, comparado a outros que utilizam proteínas, enzimas e sais de tetrazólio, mais sensível e de custo reduzido.

O mecanismo de determinação da viabilidade baseia-se na incorporação do corante pelos lisossomos das células viáveis que, sendo fracamente catiônicos, penetram membranas e se ligam a tensoativos aniônicos ou a grupos fosfatos presentes na matriz lisossomal (REPETTO et al., 2008).

As figuras 17 e 18 mostram os valores da viabilidade celular, em porcentagem, em função da concentração da formulação (livre ou encapsulada) após 24 e 48 horas do tratamento. Na Figura 17, observa-se que em concentrações pequenas $(31,25 ; 62,5 ; 125$ e 250 $\mathrm{ng} / \mathrm{mL}$ ) a formulação CLN-DOXO mostrou-se mais citotóxica do que a DOXO livre. Na concentração de $125 \mathrm{ng} / \mathrm{mL}$ a DOXO encapsulada reduziu a viabilidade em 66\% enquanto que a DOXO livre manteve a viabilidade em 95\%, indicando a maior efetividade da DOXO encapsulada. Esse aumento da atividade antitumoral foi confirmado com os valores de $\mathrm{IC}_{50}$ que reduziu 2,1 vezes quando a DOXO foi encapsulada $(191 \mathrm{ng} / \mathrm{mL})$ em relação à DOXO livre $(401,5 \mathrm{ng} / \mathrm{mL})$. Essa redução pode estar associada a maior internalização da DOXO nas células tumorais. As nanopartículas são internalizadas pelas células por vias endocíticas, resultando assim numa maior captação celular do fármaco encapsulado e, consequentemente, um maior efeito antitumoral (PURI et al., 2018, SALATIN e KHOSROUSHAHI, 2017). O mesmo perfil foi observado quando as células foram expostas aos tratamentos por 48h (Figura 18). O CLN sem DOXO não apresentou citotoxicidade para as células RT4 sendo que a viabilidade celular das células tratadas por 24 e 48 h com os CLNs sem DOXO foi superior a 86\% nas mesmas diluições usadas para as concentrações de CLN-DOXO. Dessa forma, conclui-se que o CLN não influencia na ação citotóxica da DOXO. 
Figura 17 Viabilidade de células RT4 em função das diferentes concentrações de CLN-DOXO e DOXO livre após o intervalo de 24 horas

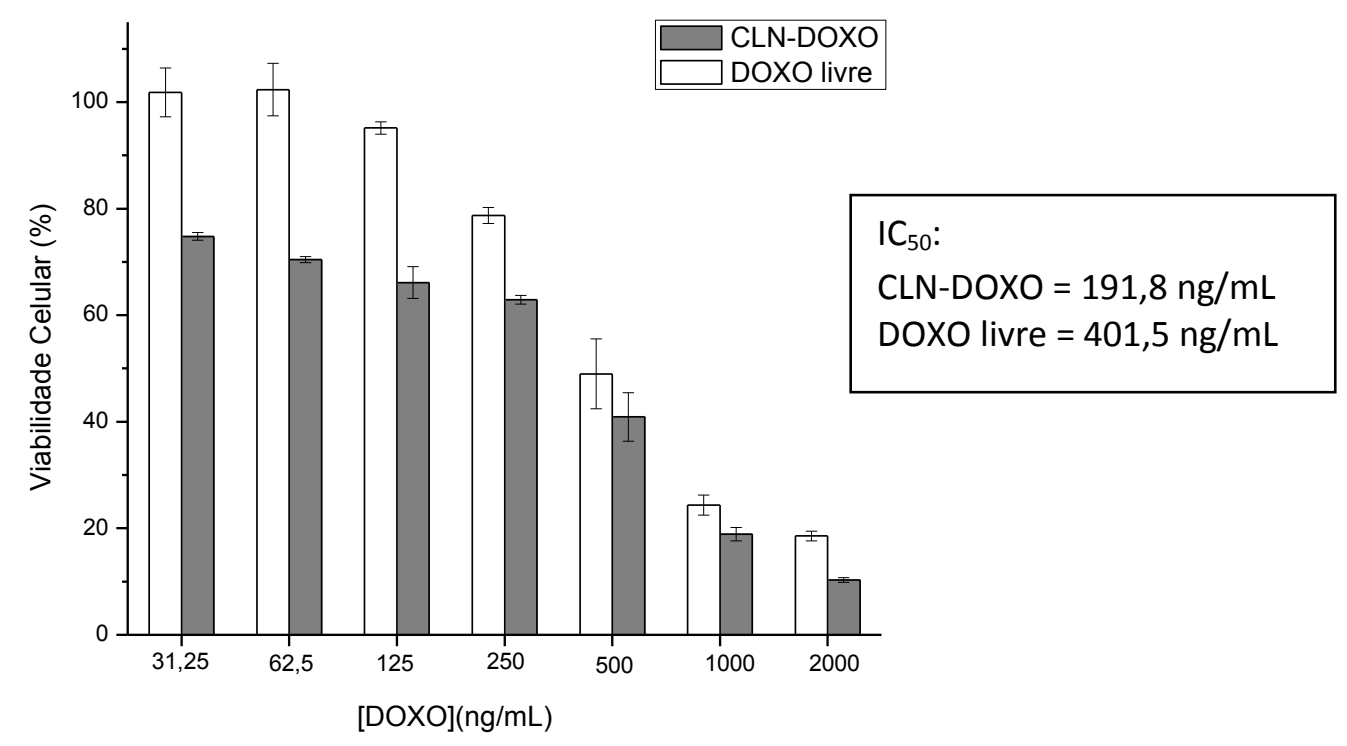

Fonte: Elaborado pelo autor

Figura 18 Viabilidade de células RT4 em função das diferentes concentrações de CLN-DOXO e DOXO livre após o intervalo de 48 horas

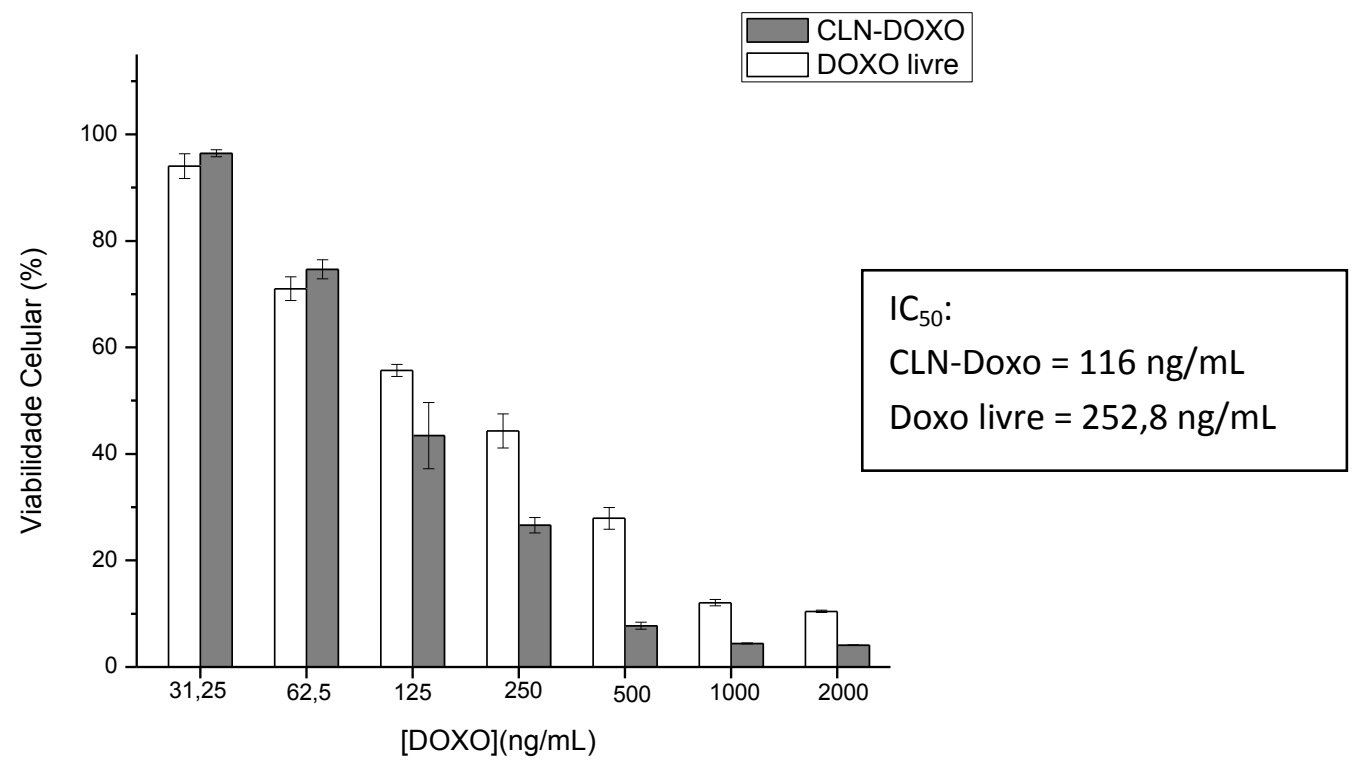

Fonte: Elaborado pelo autor 


\section{$\underline{\text { B.2. Ensaio de uptake celular por citometria de fluxo }}$}

Os sistemas nanoestruturados são capazes de entrar em células vivas por diferentes vias endocíticas aumento assim a internalização do fármaco encapsulado. A eficiência da endocitose de nanopartículas depende não apenas do tamanho das partículas, mas também da carga superficial e do revestimento da superfície. Além disso, o meio de cultura e as propriedades de absorção específicas das células desempenham um papel significativo na determinação da interação de nanopartículas com a membrana celular (SALATIN e KHOSROUSHAHI, 2017).

O uptake celular da DOXO livre em células de câncer de bexiga RT4 foi comparada com o da DOXO encapsulada (CLN-DOXO) (figura 19). Nesse ensaio a viabilidade das células, avaliada pelo iodeto de propídeo, foi de 96,8\%, sendo essa alta viabilidade adequada para esse tipo de estudo. Na figura 10 pode-se observar que houve aproximadamente o dobro de DOXO internalizada nas células quando a DOXO estava encapsulada no CLN em relação à DOXO livre. Esse resultado corrobora com os resultados de citotoxicidade, em que o aumento da internalização e a permanência da DOXO encapsulada no interior da célula aumentou a efetividade (maior citotoxicidade em relação à DOXO livre) da formulação nas células de câncer de bexiga. Esse aumento do uptake celular pode ser atribuído ao reduzido diâmetro dos CLNs e a sua composição lipídica e a presença de Pluronic na superfície das partículas. Yin et al. (2005) estudaram nanopartículas de PLGA com diferentes diâmetros para determinar a influência deste parâmetro no uptake celular por citometria de fluxo. Eles mostraram que nanopartículas de PLGA com diâmetro entre 100 e $200 \mathrm{~nm}$ apresentam alta capacidade de captação celular em relação as partículas maiores. Dessa forma, como as partículas desenvolvidas nesse trabalho apresentaram diâmetro de $112 \mathrm{~nm}$, essas tendem a apresentar alta captação celular. Além disso, o Pluronic presente na superfície das partículas pode ter contribuído para a maior internalização da DOXO. O Pluronic é utilizado nas formulações farmacêuticas e esse estabilizante pode aumentar a biodisponibilidade de fármacos com baixa solubilidade tanto pelo aumento na solubilidade como pela modulação do fluxo de fármacos dependente de glicoproteína-P (gp-P), aumentando significativamente o seu uptake em células cancerosas (WEI et al., 2013). 
Figura 19 Uptake celular da DOXO livre e do CLN-DOXO em células de câncer de bexiga RT4

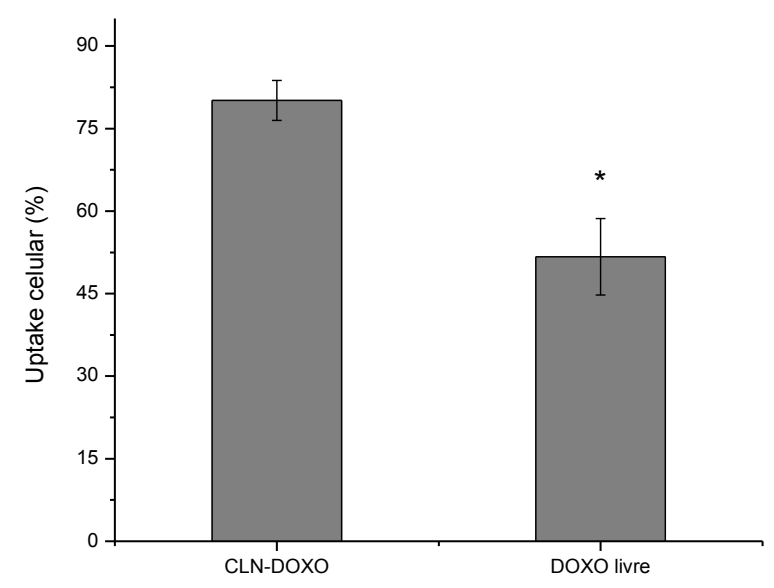

Fonte: Elaborado pelo autor

\section{Ensaios ex vivo e in vivo de permeação em bexiga de porco}

\section{C.1. Ensaio ex vivo de permeacão em bexiga de porco}

A eficácia da terapia intravesical para o câncer de bexiga é em parte limitada pela baixa permeação do fármaco no urotélio. Desta forma, a avaliação da capacidade de permeação de sistemas de liberação na bexiga é muito relevante. As imagens de microscopia confocal da Figura 20 correspondem a bexiga de porco após 1h em contato com CLN sem DOXO (A, B e C), com DOXO livre (D, E e F) e DOXO encapsulada em CLN (CLNDOXO) (G, H e I). As imagens A, D e G referem-se às imagens histológicas da bexiga em campo claro; as imagens B, E e H referem-se às imagens da fluorescência da doxorrubicina e, por fim, as imagens C, F e I referem-se às imagens com a sobreposição da fluorescência da doxorrubicina à fluorescência do DAPI. 
Figura 20 Imagens de um microscópio confocal de uma bexiga de porco após $1 \mathrm{~h}$ em contato com CLN sem DOXO (A, B e C), com DOXO livre (D, E e F) e DOXO encapsulada em CLN (CLN$\mathrm{DOXO})(\mathrm{G}, \mathrm{H}$ e I)

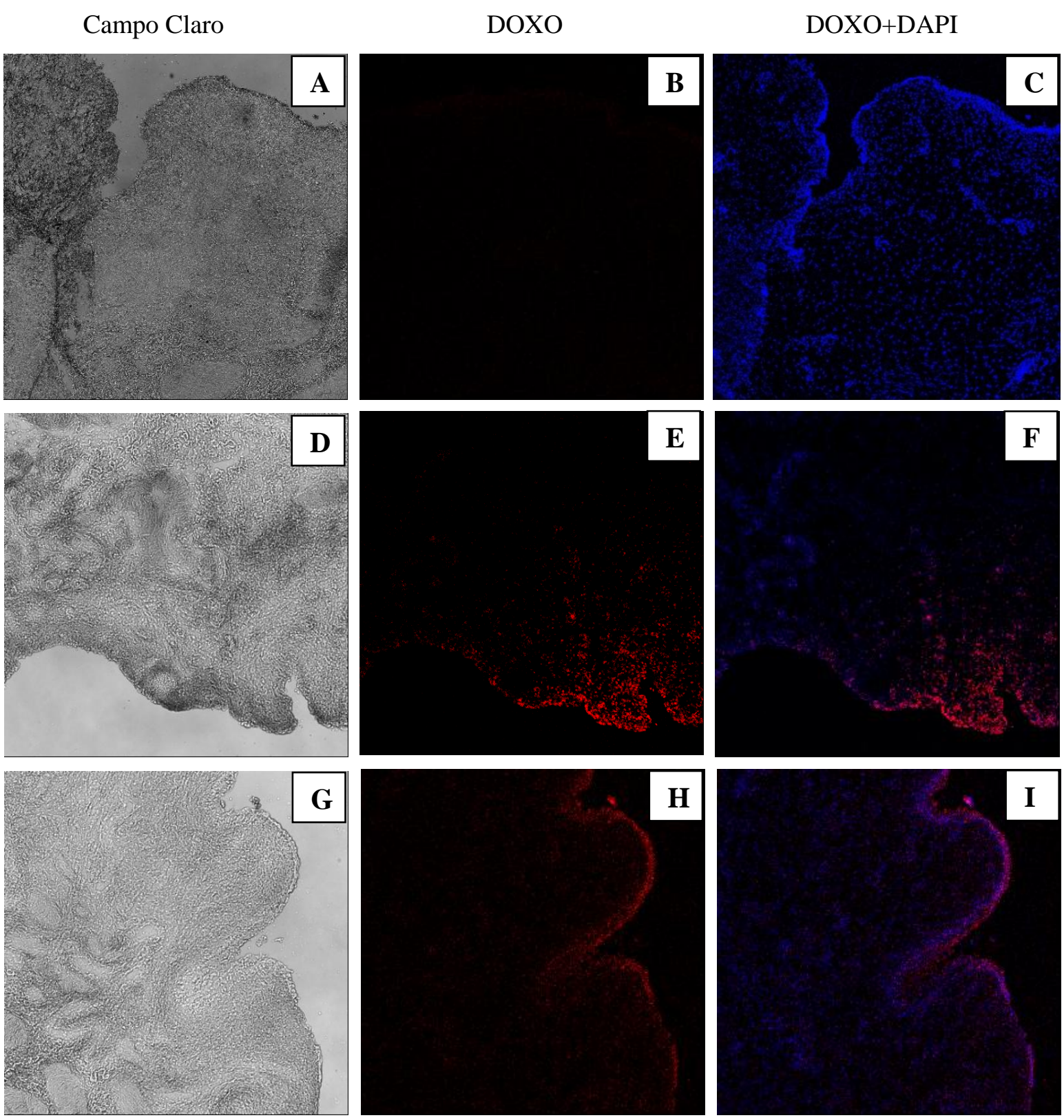

Fonte: Próprio autor

Na Figura 20B, não se observa nenhuma fluorescência pois o CLN não é fluorescente, porém observa-se a fluorescência azul dos núcleos celulares marcados por DAPI (Figura 20C). Já a DOXO livre e encapsulada apresentou fluorescência vermelha como observado nas figuras $20 \mathrm{E} \mathrm{e} \mathrm{H}$, respectivamente. Comparando estas imagens observa-se que a doxorrubicina livre penetrou e se distribuiu de forma pouco homogênea comparada às nanopartículas com o fármaco, que apresentou uma permeação mais uniforme. Esses resultados se assemelham aos 
de outro grupo de pesquisadores que encapsularam epirrubicina em nanopartículas poliméricas (CHANG et al, 2009). Nesse estudo foi avaliado a permeação ex vivo de epirrubicina live e encapsulada em bexiga de porco sendo observado baixa fluorescência e penetração limitada do urotélio do fármaco livre. Entretanto, quando o fármaco estava encapsulado foi observado uma fluorescência mais homogênea e maior intensidade de penetração no urotélio (CHANG et al, 2009).

\section{C.2. Ensaio in vivo de permeacão em bexiga de porco}

Os resultados dos ensaios de permeação em bexiga de porco in vivo estão apresentados na Figura 21. Nessa figura as imagens A e D referem-se às imagens histológicas da bexiga em campo claro; as imagens B e E referem-se às imagens da fluorescência da doxorrubicina e, por fim, as imagens C e F referem-se às imagens com a sobreposição da fluorescência da doxorrubicina à fluorescência do DAPI.

Figura 21 Imagens de um microscópio confocal de uma bexiga de porco após $1 \mathrm{~h}$ em contato com DOXO livre (A, B e C) e DOXO encapsulada em CLN (CLN-DOXO) (D, E e F).

Campo Claro
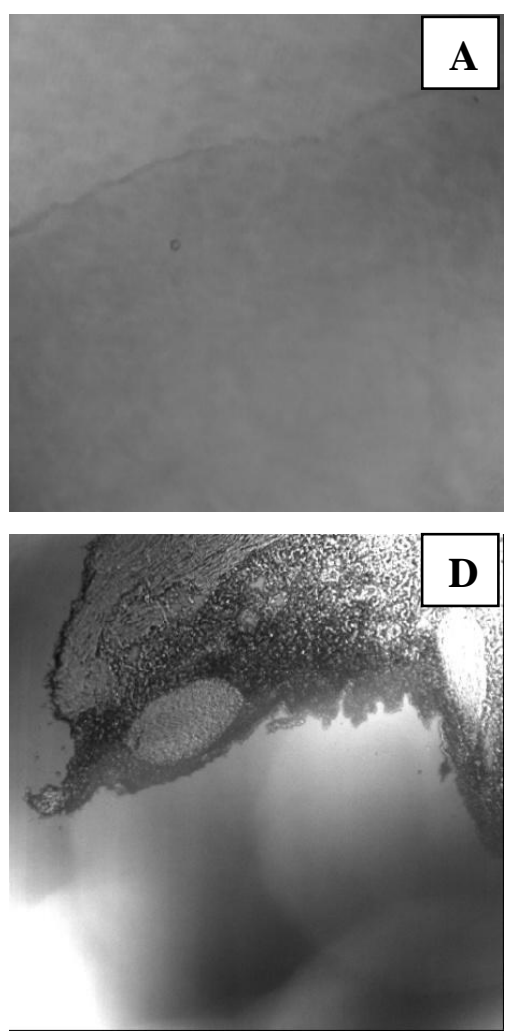

Fonte: Próprio autor
DOXO
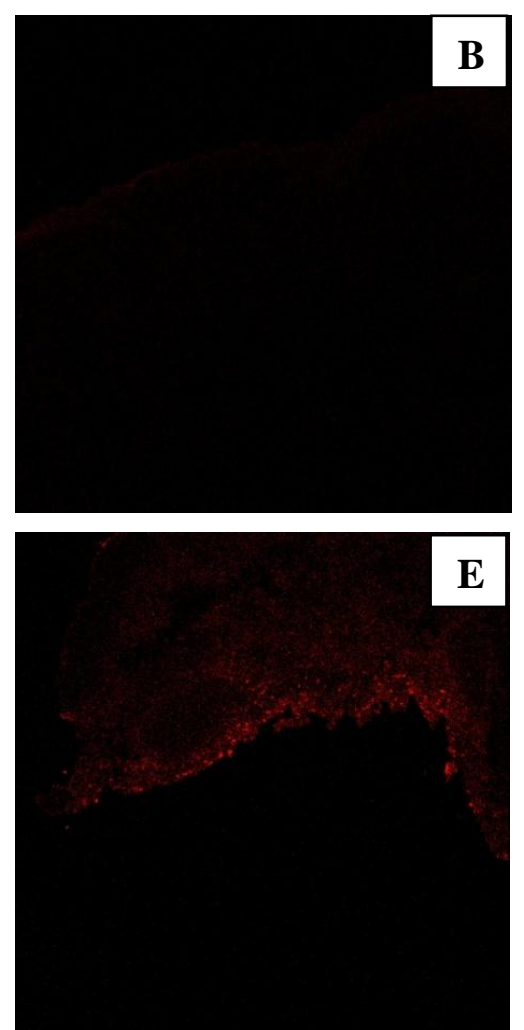

DOXO+DAPI
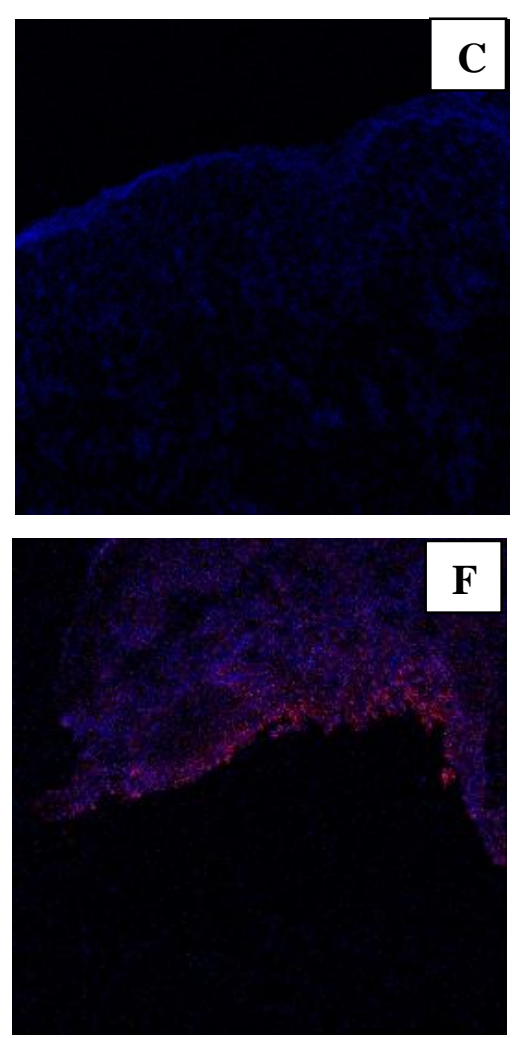
Não foi observado a fluorescência da DOXO livre na bexiga. Entretanto foi observada a fluorescência da DOXO encapsulada em CLN no urotélio e sua penetração em camadas mais profundas. Esse resultado corrobora com os resultados de mucoadesão. Possivelmente, devido à propriedade de interação do CLN com a mucina (mucoadesão), esses carreadores permaneceram aderidos na mucosa da bexiga além de aumentar a permeação e o uptake da DOXO no urotélio. O estabilizante Pluronic e o polietilenoglicol (PEG) são polímeros mucopenetrantes. Dessa forma a presença desses polímeros na superfície de nanopartículas favorece a penetração da partícula através do muco (NETSOMBOON e BERNKOPSCHNÜRCH, 2016). O revestimento de PLGA com Pluronic ${ }^{\circledR}$ F-127 mostrou uma melhora significativa na difusão de partículas em muco humano altamente viscoelástico nos seios da face, comparado com o PLGA não revestido (LAI et al., 2011). Resultados similares foram obtidos por $\mathrm{Li}$ et al. (2011) com lipossomas revestidos com Pluronic. Dessa forma, a formulação desenvolvida é interessante para a terapia do câncer de bexiga devido a sua permeação no urotélio que poderá aumentar a eficácia do tratamento e reduzir o número de instilações. 
V. Conclusão 


\section{CONCLUSÃO}

Carreadores lipídicos nanoestruturados (CLN) preparados neste estudo apresentaram alta eficiência de encapsulamento ( 94\%), tamanho ao redor de $112 \mathrm{~nm}$ e índice de polidispersão inferior a 0,2 indicando que o método de emulsão à quente e sonicação e a composição dos CLNs foram adequados para o encapsulamento da doxorrubicina (DOXO) nos CLN e para a obtenção de uma formulação em escala nanométrica e com baixa polidispersão. $\mathrm{O}$ encapsulamento da DOXO não influenciou, de forma significativa, as propriedades físicas dos carreadores. O potencial zeta das partículas foi negativo e estas apresentaram alta estabilidade no período de 60 dias. Além disto, os CLN-DOXO foram estáveis na faixa de $\mathrm{pH}$ de 6-8 e apresentaram propriedade de mucoadesão.

O encapsulamento da DOXO em CLN aumentou a sua atividade antitumoral in vitro, diminuindo o $\mathrm{IC}_{50}$, devido, provavelmente ao maior uptake dos CLN nas células de câncer de bexiga. $\mathrm{O}$ encapsulamento também aumentou a permeação da DOXO no urotélio tanto nos ensaios de permeação ex vivo como nos ensaios in vivo, sendo que nesse ultimo só foi detectada DOXO nas bexigas tratadas com CLN-DOXO. Ademais, os resultados indicam que os nanocarreadores lipídicos veiculando DOXO e desenvolvidos neste trabalho compõe um sistema interessante para a futura terapia do câncer de bexiga. 
VI. Referências 


\section{REFERÊNCIAS}

ALI, H. S. M; YORK, P.; ALI, A. M. A.; BLAGDENA, N. Hydrocortisone nanosuspensions for ophthalmic delivery: A comparative study between microfluidic nanoprecipitation and wet milling. J. Control. Release; v. 149, p. 175-181, 2011

ANDREAS, B. O.; BRANDAU, S. Immune mechanisms in bacillus Calmette Guerin imunotherapy for superficial bladder cancer. J Urol.; v.170, p.964-969, 2003.

ARORA, S.; RAJWADE, J. M.; PAKNIKAR, K. M. Nanotoxicology and in vitro studies: The need of the hour. Toxicology and Applied Pharmacology; v. 258, p. 151-165, 2012.

BAHARI, L. A. S.; HAMISHEHKAR, H. The impact of variables on particles size of solid lipid nanoparticles and nanostructured lipid carriers; a comparative literature review. Adv. Pharm. Bull.; v. 6, p. 143-151, 2016.

BHOLE, A.; BRANDAU, S. Imune mechanisms in bacillus Calmette Guerin Immunotherapy for superficial bladder cancer. J Urol.; v.170, p. 964-969, 2003.

BRASIL. Ministério da Saúde. Departamento de Informática do SUS. Sistema de informações sobre mortalidade. Brasília, DF, 2017. Disponível em: <http://www.datasus.gov.br>. Acesso em: 01 de maio de 2018.

CAPAZ, F. R.; SABAN, R.; BONAMINI, L. V. Vias de administração de fármacos. In: Luiz Biela de Sousa Vale; Ricardo Martins de Oliveira Filho; Roberto de Lucia; Seizi Oga. (Org.). Farmacologia Integrada, São Paulo: Editora Atheneu; v. 1, p. 21-32, 1988.

CHANG, L.; WU, S.; TSAI, J.; YU, T.; TSAI, T. Optimization of epirubicin nanoparticles using experimental design for enhanced intravesical drug delivery. Int. J. Pharmaceut.; v. 376, p. 195-203, 2009.

FERLAY, J. et al. GLOBOCAN 2012 v1.0, cancer incidence and mortality worldwide. Lyon, France: IARC, 2013. (IARC CancerBase, 11). Disponível em: 〈http://globocan.iarc.fr>. Acesso em: 04 de maio de 2018.

FREEDMAN, N. D. et al. Association between smoking and risk of bladder cancer among men and women. Journal of the American Medical Association, Chicago, v. 306, n. 7, p. 737-745, 2011.

GANI, S. S. A.; BASRI, M.; RAHMAN, M. B. A.; KASSIM, A.; RAHMAN, R. N. Z. R. A.; SALLEH, A. B.; ISMAIL, Z. "Characterization and effect on skin hydration of engkabangbased emulsions”. Biosci. Biotechnol. Biochem., v. 74, n. 6, p. 1188-1193, 2010.

GESZKE-MORITZ, M.; MORITZ, M. Solid lipid nanoparticles as attractive drug vehicles: Composition, proprerties and therapeutic strategies. Material Science and Engineering C. v.68, p. 982-994. 2016.

GLOBOCAN 2008, http://globocan.iarc.fr/. Acesso em 01 de novembro de 2017.

GRASSO, M. Bladder Cancer: A Major Public Health Issue. Eur. Urol. Suppl.; v.7, p. 510 $515,2008$. 
GUHASARKAR, S.; BANERJEE, R. Intravesical drug delivery: Challenges, current status, opportunities and novel strategies. J. Control. Release v. 148, p. 147-59, 2010.

HERR, H. W.; DALBAGNI, G.; DONAT, S. M. Bacillus calmette-guerin without maintenance therapy for hig-risk non-muscle-invasive bladder cancer. European Urology. v. 60, p. 32-36. 2011.

HARIVARDHAN REDDY, L.; SHARMA, R.K.; CHUTTANI, K., MISHRA, A.K.; MURTHY, R.S. Influence of administration route on tumor uptake and biodistribution of toposide loaded solid lipid nanoparticles in Dalton's lymphoma tumor bearing mice. J. Control. Release, v. 105, p. 185-198, 2005.

INCA - INSTITUTO NACIONAL DE CÂNCER. Incidência de câncer no Brasil - Estimativa 2018. Brasília, 2018. 126 p.

JIANG, W.; ROEMELING, C. A.; CHEN, Y.; QIE, Y.; LIU, X.; CHEN, J.; KIM, B. Y. S. Designing nanomedicine for immuno-oncology. Nature Biomedical Engineering; v. 1, p. 111, 2017.

KROFT, S. H.; OYASU. R. Urinary bladder cancer: mechanisms of development and progression. Lab Invest.; v.71, p.158-174, 1994.

LAI, S. K.; SUK, J. S.; PACE, A.; WANG, Y. -Y.; YANG, M.; MERT, O. Drug carrier nanoparticles that penetrate human chronic rhinosinusitis mucus. Biomaterials; v. 32, p. 6285-6290, 2011.

LI, X.; CHEN, D.; LE, C.; ZHU, C.; GAN, Y.; HOVGAARD, L. Novel mucus-penetrating liposomes as a potential oral drug delivery system: preparation, in vitro characterization, and enhanced cellular uptake. Int. J. Nanomed.; v. 6, p. 3151-3162, 2011.

LIN, J. J.; CHEN, J. S., HUANG, S. J.; KO, J. H.; WANG, Y. M.; CHEN, T. L.; WANG, L. F. Folic acid-Pluronic F127 magnetic nanoparticle clusters for combined targeting, diagnosis, and therapy applications. Biomaterials; v. 30, p. 5114-5124, 2009.

LIN, P.; LIN, S.; WANG, P. C.; SRIDHAR, R. Techniques for physicochemical characterization of nanomaterials. Biotechnology Advances, v. 32, p. 711-726, 2014.

LIU, C.-H.; WU, C.-T. Optimization of nanostructured lipid carriers for lutein delivery. Colloids Surf. A Physicochem. Eng. Asp.; v. 353, p. 149-156, 2010.

MADANE, R.G.; MAHAJAN, H.S. Curcumin-loaded nanostructured lipid carriers (NLCs) for nasal administration: design, characterization, and in vivo study. Drug Deliv., v. 23, p. 1326-34, 2016.

MARCATO, P. D. Preparação, caracterização e aplicações em fármacos e cosméticos de nanopartículas lipídicas sólidas. Revista Eletrônica de Fármacia; v. 6, p. 1-37, 2009.

MELO, P.S.; DE MEDEIROS CAVALCANTE, H.M.; HAUN, M. Warifteine and milonine, alkaloids isolated from Cissampelos sympodialis Eichl: cytotoxicity on rat hepatocyte culture and inV79 cells. Toxicol Lett.; v. 142, p. 143-51, 2003.

MANOHARAN, M. Intravesical therapy for urothelial carcinoma of the bladder. Indian Journal of Urology: IJU : Journal of the Urological Society of India; v. 27, p. 252-261, 2011. 
MIRYAGHOUBZADEH, J.; DARABI, M.; MADAEN, K.; SHAAKER, M.; MEHDIZADEH, A.; HAJI-HOSSEINI, R. Tissue fatty acid composition in human urothelial carcinoma. Br. J. Biomed. Sci.; v. 70, p. 1-5, 2013.

MORALES, A.; EIDINGER, D.; BRUCE, A. W. Bacillus Calmette-Guerin in the treatment of adenocarcinoma of the kidney. J. Urol., v. 115, p. 377-380, 1976.

NAHAK, P.; KARMAKAR, G.; CHETTRI, P.; ROY, B.; GUHA, P.; BESRA, S. E.; SOREN, A.; BYKOV, A. G.; AKENTIEV, A. V.; NOSKOV, B. A.; PANDA, A. K. Influence of lipid core material on physicochemical characteristics of an ursolic acidloaded nanostructured lipid carrier: an attempt to enhance anticancer activity. Langmuir; v. 32, p. 9816-9825, 2016.

NETSOMBOON, K.; BERNKOP-SCHNURCH, A. Mucoadhesive vs. mucopenetrating particulate drug delivery. Eur. J. Pharm. Biopharm.; v. 98, p. 76-89, 2016.

OLIVEIRA, M. S.; MUSSI, S. V.; GOMES, D. A.; YOSHIDA, M. I.; FREZARD, F.; CARREGAL, V. M.; FERREIRA, L. A. M. $\alpha$-Tocopherol succinate improves encapsulation and anticancer activity of doxorubicin loaded in solid lipid nanoparticles. Colloids Surf. B Biointerfaces; v. 140, p. 246-253, 2016.

PIKTEL, E.; NIEMIROWICZ, K.; WATEK, M.; WOLLNY, T.; DEPTULA, P.; BUCKI, R. Recent insights in nanotechnology-based drugs and formulations designed for effective anti-cancer therapy. J. Nanobiotechol.; v. 14, p. 1-23, 2016.

PURI, R.; ADESINA, S.; AKALA, E. Cellular uptake and cytotoxicity studies of pHresponsive polymeric nanoparticles fabricated by dispersion polymerization. J. Nanosci. Nanotechnol.; v. 2, p. 3-16, 2018.

REIS, L.O.; FERREIRA, U.; BILLIS, A.; CAGNON, V. H.; FÁVARO, W. J. Antiangiogenic effects of the superantigen staphylococcal enterotoxin B and bacillus CalmetteGuérin immunotherapy for nonmuscle invasive bladder cancer. J. Urol.; v.187, p.438-445, 2012.

REIS, L. O.; PEREIRA, T. C.; FAVARO, W. J.; CAGNON, V. H.; LOPES-CENDES, I.; FERREIRA, U. Experimental animal model and RNA interference: a promising association for bladder cancer research. World J. Urol.; v.27, p.353-361, 2009.

SALATIN, S.; KHOSROUSHAHI, A. I. Overviews on the cellular uptake mechanism of polysaccharide colloidal nanoparticles. J. Cell. Mol. Med.; v. 21, p. 1668-1686, 2017.

SCHWARZ, J. C., WEIXELBAUM, A., PAGITSCH, E. Nanocarriers for dermal drug delivery: Influence of preparation method, carrier type and rheological properties. Int. J. Pharm.; v. 437, p. 83-88, 2012.

SENYIGIT, Z. A.; KARAVANA, S. Y.; ILEM-OZDEMIR, D.; ÇALISKAN, Ç.; WALDNER, C.; SEN, S.; BERNKOP-SCHNURCH, A.; BALOGLU, E. Design and evaluation of an intravesical delivery system for superficial bladder cancer: preparation of gemcitabine $\mathrm{HCl}$-loaded chitosan-thioglycolic acid nanoparticles and comparison of chitosan/poloxamer gels as carriers. Int. J. Nanomedicine; v. 10, p. 6493-507, 2015. 
SHELlEY, M. D.; MASON, M. D.; KYNASTON, H. Intravesical therapy for superficial bladder cancer: a systematic review of randomized trial and meta-analyses. Cancer Treat Rev.; v. 36, p. 295-205, 2010.

SHIMADA, K., Fujii, T.; Anai, S.; Fujimoto, K,; Konishi, N. ROS generation via NOX4 and its utility in the cytological diagnosis of urothelial carcinoma of the urinary bladder. BMC Urology; v. 11, p. 1-12, 2011.

STEWART, B. W.; WILD, C. P. (Ed.). World Cancer Report: 2014. Lyon: IARC, ISBN: 97892-832-0443-5, 2014.

SUBEDI, R. K.; KANG, K. W.; CHOI, H. K. Preparation and characterization of solid lipid nanoparticles loaded with doxorubicin. Eur. J. Pharm. Sci.; v.37, p.508-513, 2009.

SUN, M.; NIE, S.; PAN, X.; ZHANG, R.; FAN, Z.; WANG, S. Quercetin-Nanostructured lipid carriers: Characteristics and anti-breast cancer activities in vitro. Coll and Surfaces B: Biointerfaces v. 113, p. 15-24, 2014.

SVILENOV, H.; TZACHEV, C. Solid Lipid Nanoparticles - A Promising Drug Delivery System, Nanomedicine; Editores Seifalian A.; Mel, A. de; Kalaskar, D. M.; p. 187-237, 2014.

TOMASINA J.; POULAIN L.; ABEILARD E.; GIFFARD F.; BROTIN E.; CARDUNER L.; CARREIRAS F.; GAUDUCHON P.; RAULT S.; MALZERT-FRÉON A. Rapid and Soft Formulation of Folate-Functionalized Nanoparticles for the Targeted Delivery of Tripentone in Ovarian Carcinoma. Int. J. Pharm. 2013, 458, 197-207.

TRABOULSI, S. L.; KASSOUF, W. A review of neoadjuvant and adjuvant chemotherapy for nonmetastatic muscle invasive bladder cancer. Urol. Practice J.; v. 3, p. 41-49. 2016.

TRAPANI, A.; PALAZZO, C.; CONTINO, M.; PERRONE, M.G.; CIOFFI, N.; ITARANTO, N.; COLABUFO, N.A.; CONESE, M.; TRAPANI, G.; PUGLISI.; Mucoadhesive Properties and Interaction with P-Glycoprotein (P-gp) of Thiolated-Chitosans and -Glycol Chitosans and Corresponding Parent Polymers: A Comparative Study. Biomacromolecules. 2014, v.15, p.882-893.

TRÉDAN O., GALMARINI C. M., PATEL K., TANNOCK I. F. Drug resistance and the solid tumor microenvironment. J. Natl. Cancer Inst.; v.99, p.1441-1454, 2007.

TSALLAS, A.; JACKSON, J.; BURT, H. The uptake of paclitaxel and docetaxel into ex vivo porcine bladder tissue from polymeric micelle formulations. Cancer Chemother. Pharmacol.; v.68, p.431-444, 2011.

VARSHOSAZ, J.; HASSANZADEH, F.; SADEGHI, H.; SHAKERY, M. Folate Targeted Solid Lipid Nanoparticles of Simvastatin for Enhanced Cytotoxic Effects of Doxorubicin in Chronic Myeloid Leukemia. Curr. Nanosci.; v. 8, p. 249-258, 2012.

WALSH, P. C.; RETIK, A. B.; VAUGHAN, E. D. Campbell's Urology.; 7 ed. Philadelphia, Pennsylvania: W.B. Saunders Company, ISBN: 9781416029687; 2007.

WEI, Z.; YUAN, S.; HAO, J.; FANG, X. Mechanism of inhibition of P-glycoprotein mediated efflux by Pluronic P123/F127 block copolymers: Relationship between copolymer concentration and inhibitory activity. European Journal of Pharmaceutics and Biopharmaceutics, v. 83, p. 266-274, 2013. 
WIENTJES, M. G.; BADAlAMENT, R. A.; AU, J. L.-S. Penetration of intravesical doxorubicin in human bladders. Cancer Chemother. Pharmacol.; v. 37, p. 539-546, 1996.

YIN WIN, K.; FENG, S. S. Effects of particle size and surface coating on cellular uptake of polymeric nanoparticles for oral delivery of anticancer drugs. Biomaterials, v. 26, n. 15, p. 2713-2722, 2005.

ZIMMERMANN, E.; SOUTO, E. B.; MULLER, R. H. Physicochemical investigations on the structure of drug-free and drug-loaded solid lipid nanoparticles (SLN) by means of DSC and ${ }^{1} \mathrm{H}$ NMR. Pharmazie; v. 60, p. 508-513, 2005

ZWICKE, G. L.; MANSOORI, G. A.; JEFFERY, C. J. Utilizing the folate receptor for active targeting of cancer nanotherapeutics. Nano Rev.; v.3, 18496, 2012. 